\title{
Individual diet variation in a marine fish assemblage: Optimal Foraging Theory, Niche Variation Hypothesis and functional identity
}

\author{
Cachera Marie ${ }^{1,2,4}$, Ernande Bruno ${ }^{2,{ }^{*}}$, Villanueva Ching-Maria ${ }^{3}$, Lefebvre Sebastien ${ }^{4}$
}

1 LEMAR, UMR 6539 CNRS, IUEM, UBO, Technopôle Brest Iroise, 29280 Plouzané, France

2 IFREMER, Laboratoire Ressources Halieutiques, Boulogne sur Mer, France

${ }^{3}$ IFREMER, Centre de Bretagne, Unité Sciences et Technologies Halieutiques, Z.I. Pointe du Diable, CS10070, 29280 Plouzané, France.

${ }^{4}$ Univ. de Lille, CNRS, ULCO, UMR 8187 LOG « Laboratoire d'Océanologie et Géosciences », 28

avenue Foch, 62930 Wimereux, France

* Corresponding author : Bruno Ernande, email address : $\underline{\text { bruno.ernande@ifremer.fr }}$

\begin{abstract}
:
Individual diet variation (i.e. diet variation among individuals) impacts intra- and inter-specific interactions. Investigating its sources and relationship with species trophic niche organization is important for understanding community structure and dynamics. Individual diet variation may increase with intra-specific phenotypic (or "individual state") variation and habitat variability, according to Optimal Foraging Theory (OFT), and with species trophic niche width, according to the Niche Variation Hypothesis (NVH). OFT proposes "proximate sources" of individual diet variation such as variations in habitat or size whereas NVH relies on "ultimate sources" related to the competitive balance between intra- and inter-specific competitions. The latter implies as a corollary that species trophic niche overlap, taken as inter-specific competition measure, decreases as species niche width and individual niche variation increase. We tested the complementary predictions of OFT and NVH in a marine fish assemblage using stomach content data and associated trophic niche metrics. The NVH predictions were tested between species of the assemblage and decomposed into a between- and a withinfunctional group components to assess the potential influence of species' ecological function. For most species, individual diet variation and niche overlap were consistently larger than expected. Individual diet variation increased with intra-specific variability in individual state and habitat, as expected from OFT. It also increased with species niche width but in compliance with the null expectation, thus not supporting the NVH. In contrast, species niche overlap increased significantly less than null expectation with both species niche width and individual diet variation, supporting NVH corollary. The between- and within-functional group components of the NVH relationships were consistent with those between species at the assemblage level. Changing the number of prey categories used to describe diet (from 16 to 41) did not change the results qualitatively. These results suggest that, besides proximate sources, intra-specific competition favors higher individual diet variation than expected while interspecific competition limits the increase of individual diet variation and of species niche overlap with species niche expansion. This reveals partial trophic resources partitioning between species. Various niche metrics used in combination allow inferring competition effects on trophic niches' organization
\end{abstract}


within communities.

\section{Highlights}

- Optimal Foraging Theory and Niche Variation Hypothesis were tested for complementary predictions of feeding strategies in a marine fish assemblage/ - Competitive effects were inferred from a combination of various trophic niche metrics/ Individual diet variation was verified based on OFT in contrast to NVH which was only partly supported/ Intra-specific competition favors higher individual diet variation while inter-specific competition limits it/ - Our results revealed a partial trophic resource partitioning between fish species

Keywords : specialization, trophic similarity, size-dependent diet variation, English Channel, semienclosed sea 


\section{Introduction}

During the last decade, an increasing number of authors called for consideration of individual niche variation in community ecology (Albert et al., 2012; Bolnick et al., 2011; Pachepsky et al., 2007). In trophic ecology, individual diet variation (or individual trophic niche variation, i.e. diet variation among individuals) is known to be a relatively common phenomenon (Bolnick et al., 2007, 2003) that alters the average competitive pressure between conspecifics or with individuals from other species. Thus, individual diet variation may affect both prey and predator population dynamics that, together, may ultimately have important implications on trophic network structure and dynamics (Araùjo et al., 2011; Svanbäck and Bolnick, 2008).

Considering such ecological consequences, it is essential to document the patterns and to understand the causes of individual diet variation. Optimal Foraging Theory (OFT) suggests that individual diet variation depends on individuals' phenotype (or "individual state" such as size, sex or developmental stage) and prey availability (Schoener, 1971; Svanbäck and Bolnick, 2005; Werner and Hall, 1974). More precisely, although an individual is able to consume a wide diversity of prey items, it may adopt and feed on specific organisms depending on energetic benefits relative to handling time costs. Such benefits will depend on the individual's state and on prey species availability in its habitat. Consequently, individual state and habitat variation between conspecifics may be seen as "proximate sources" of individual diet variation (Araùjo et al., 2011).

Another source of individual diet variation is described by Van Valen's "Niche Variation Hypothesis" (NVH, Van Valen, 1965). It is related to the selective forces responsible for individual specialization and, thus, can be qualified as an "ultimate source" of individual diet variation that is complementary to the proximate sources proposed by the OFT. More 
specifically, the NVH indicates that a larger individual niche variation should be associated with a wider species ecological niche. In trophic terms, a species with a large trophic niche is expected to be composed of individuals that specialize on different diets. According to the $\mathrm{NVH}$, individual diet variation and species trophic niche width can be interpreted as resulting from the interplay between intra- and inter-specific competition (Araùjo et al., 2011; Bolnick et al., 2003). Strong intra-specific competition for food resources is expected to promote species trophic niche expansion as individuals tend to diversify their diet so as to reduce competition between conspecifics (Bolnick et al., 2011, 2003; Svanbäck and Bolnick, 2007; Svanbäck and Persson, 2004; Tinker et al., 2012). In contrast, strong inter-specific competition may force individuals to forage on a few prey items in order to mitigate interactions with other species, thus inducing species niche contraction. Inter-specific competition also favors trophic niche diversification or resource partitioning across species according to the principles of competitive exclusion and character displacement (Schluter, 1996; Svanbäck et al., 2008). To summarize, species trophic niche width and individual diet variation may depend on the balance between intra- and inter-specific competitions (termed as "competitive balance" hereafter). Therefore, 3 different patterns may be expected under the NVH. First, a positive relationship between trophic niche width and individual diet variation is expected as the main prediction. Second, a negative (positive) relationship between inter(intra-)specific competition and species trophic niche width is predicted as a corollary. Third, a negative (positive) relationship between inter-(intra-)specific competition and individual diet variation is also expected as a corollary. These 3 patterns should apply if, and only if, resources are limiting.

The NVH was previously tested on color polymorphism maintenance in birds (Galeotti and Rubolini, 2004), on skull and canine shapes considered as surrogates for size and feeding 
niche, respectively, in terrestrial carnivores (Meiri et al., 2005), and on genetic variation used as an indicator of phenotypic variation in marine fishes (Somero and Soulé, 1974). Surprisingly, despite its obvious relevance for trophic ecology, only one study tested the NVH on trophic niche (Bolnick et al., 2007). These authors correlated species trophic niche width with individual diet variation across populations, but within taxa, of fish, frogs, lizards and whelk. The NVH was successfully supported in all 4 taxa as trophic niche width increased with individual diet variation. However, this study did not provide the opportunity to test the implication of the competitive balance as it was based on comparing different populations of the same taxa belonging to distant ecosystems. A way to assess the involvement of the competitive balance in the NVH would be to compare the trophic niches of different species from the same community which may be potentially competing for food resources.

Another unexplored aspect of the NVH is how it relates to a species' ecological function or role. It is generally admitted that intra- and inter-specific trait variation influences the ecological function of species and, hence, ecosystem functioning (Cianciaruso et al., 2009; Petchey and Gaston, 2006). Influential traits are generally referred to as functional effect traits. Species performing particular ecological functions are generally expected to be characterized by highly specialized functional effect traits. It may then be hypothesized that, as specialists, they have a narrow ecological niche and they exhibit little individual niche variation (Devictor et al. 2010). On the opposite, species performing diversified functions can be expected to have a broad niche potentially allowing for high individual niche variation. If this hypothesis is true, then the type of function performed by species should determine their location along the co-gradient of niche width and individual niche variation expected under the NVH at the community level (i.e., across species). Species performing specialized functions should be located on the left side of the co-gradient characterized by a narrow niche 
and weak individual niche variation. In contrast, species performing diversified functions should be located on the right side characterized by a wide niche and high individual niche variation. As a result, species belonging to the same functional group should be grouped around the same location along the co-gradient of niche width and individual niche variation. $\mathrm{NVH}$ is thus expected to be observed between functional groups. Beyond between-functional group considerations, co-variation of niche width and individual niche variation withinfunctional groups can also be questioned. Due to closer species packing within functional groups, the effects of the balance between intra- and inter-specific competitions may be exacerbated. It is therefore interesting to assess whether the NVH also holds within functional groups. A way to assess how the NVH is related to species ecological function would be to decompose the co-variation between niche width and individual niche variation at the community level into a between- and a within-functional group components (Fig. 1). The same of course holds for NVH corollary predictions involving either inter- and intra-specific competitions.

The objective of this paper was to investigate the potential sources of among-individual diet variation and between-species niche width variation within a marine fish assemblage by testing the complementary predictions of OFT and NVH. More precisely, the aims were to (i) assess the influence of individual state and habitat on individual diet variation and (ii) test whether NVH occurs between species within the assemblage as well as (iii) between- and within-functional species groups. An assemblage of 16 marine fish species, belonging to the community of the eastern English Channel, is taken as a case study. Characteristics of species trophic niches, namely species trophic niche width, species diet overlap taken as an indicator of potential inter-specific competition and individual diet variation were estimated. Firstly, following OFT, 4 potential "proximate" sources of individual diet variation related to 
individual state and habitat were investigated. These sources include individual length, sex, sexual maturity and community of origin taken as a proxy of habitat and prey availability. Secondly, the 3 relationships expected from the $\mathrm{NVH} \mathrm{-} \mathrm{(1)} \mathrm{a} \mathrm{positive} \mathrm{relationship} \mathrm{between}$ species trophic niche width and individual diet variation, (2) a negative relationship between species trophic niche width and species diet overlap (inter-specific competition), and (3) a negative relationship between individual diet variation and species diet overlap - were tested. Thirdly, species were assigned to functional groups according to 3 alternative classifications based on species habitat and life history, diet, and phylogeny, respectively. The 3 relationships expected from the $\mathrm{NVH}$ were then tested between- and within-functional groups for these 3 classifications.

\section{Materials and methods}

\subsection{Sample collection}

Sixteen fish species (Table 1), representing a wide range of trophic diversity, were collected in the eastern English Channel during the Channel Ground Fish Survey (CGFS) operated by IFREMER in October 2009 (Fig. 2). Fishes were caught on board RV "Gwen Drez" by towing a high opening demersal trawl (GOV) with a cod-end of $20 \mathrm{~mm}$ stretched mesh for 30 minutes at a speed of approximately 3.5 knots. A spatially stratified sampling scheme was used where the area, subdivided into $15^{\prime} \times 15^{\prime}$ rectangles in which the GOV trawl, was fished at least once (Fig. 2). Following their capture, focal fish species were identified and individually labeled, frozen on board with liquid nitrogen to stop digestion and then kept frozen until further use. In the laboratory, sampled fishes were defrosted, measured for their total length ( $L, \mathrm{~cm})$, and dissected. Sex $(S)$ and maturity status $(M)$ were determined by visual 
inspection of the gonads. Digestive tracts were extracted and their contents spread and kept in Petri dishes for analysis.

\subsection{Habitat and prey availability}

Habitat and prey availability were assessed through spatial variation in the composition of the invertebrate and vertebrate demersal community captured in the same hauls as fishes during the sampling period. A hierarchical agglomerative clustering using Ward's minimum variance method with Euclidean distance, which is adapted to binary data (see Legendre and Legendre, 2012), was applied to species' presence-absence data. This clustering procedure identified 3 main demersal communities in the eastern English Channel (Fig. 2 and Table A.1). Spatial location of the 3 communities was considered as reflecting habitat variation for the studied fish species since community composition generally relates to variation in both abiotic (e.g. physico-chemical parameters) and biotic conditions (e.g. prey availability and the presence of competitors and predators; Martin et al., 2010). Each individual captured was consequently assigned a community membership ( $C$ ) according to its sampling location. These analyses were conducted with the software R (R Core Team, 2015).

\subsection{Digestive tract analysis}

Preys in digestive tract contents were identified to the lowest possible taxon under a stereomicroscope (Olympus SZX 16®), sorted, counted and weighted (0.1 g) in 853 available and non-empty digestive tracts. 96 empty digestive tracts were excluded from the analysis and parasites (platyhelminths and nematodes) were not taken into account in the fish diet. Prey items were then grouped into 41 or 16 categories combining taxonomic level and functional characteristics (Table A1. For each studied species $j$, an individual-level diet matrix $\mathbf{N}_{j}$ containing the numbers of items $N_{i j k}$ per prey category $k$ (columns) in the digestive tract of 
each individual $i$ (rows) was built. Then, for each species $j$, the proportion $p_{i j k}$ of prey category $k$ in an individual $i$ 's diet was calculated on the basis of prey counts according to:

$$
p_{i j k}=\frac{N_{i j k}}{\sum_{k^{\prime}} N_{i j k^{\prime}}} .
$$

A similar index was computed at the species level, $p_{j k}$, by averaging the proportion of prey category $k$ in the diet across all individuals of the fish species $j$ :

$$
p_{j k}=\frac{1}{n_{j}} \sum_{i=1}^{n_{j}} p_{i j k} .
$$

with $n_{j}$ as the number of individuals sampled in fish species $j$.

\subsection{Statistical analyses}

\subsubsection{Trophic niche metrics and null models}

First, trophic niche width was determined for each species $j$ using Levin's index $B_{j}$ based on species diet relative composition $p_{j k}$ :

$$
B_{j}=\frac{1}{\sum_{k} p_{j k}^{2}} .
$$

This index tends to approach the value of 1 when a species has a narrow trophic niche (feeds only on one prey category), and increases with niche width (increasing diversity of food resources, Levin, 1968). 
Second, diet similarity between species (niche overlap) was used as an indicator of potential inter-specific competition. It was calculated using pairwise proportional similarity indices $P S_{j j^{\prime}}$ species $j$ and $j^{\prime}$ (Schoener, 1968).

$$
P S_{j j^{\prime}}=1-0.5 \sum_{k}\left|p_{j k}-p_{j^{\prime} k}\right|
$$

$P S_{j j^{\prime}}$ is equal to 1 when species $j$ and $j^{\prime}$ have perfectly similar diet relative compositions (proportions $p_{j k}$ are $p_{j^{\prime} k}$ equal), and is 0 in case of completely dissimilar diet relative compositions. For each species, the mean pairwise similarity index or average species trophic niche overlap, $P S_{j}=\sum_{j^{\prime}} P S_{j j^{\prime}} /(n-1), n$ being the number of species under study, was used as an estimate of overall potential inter-specific competitive pressure experienced by species $j$.

Third, in order to estimate individual diet variation, an adaptation of the proportional similarity index, $P S_{i j}$, was used following Bolnick et al., (2002) and Araújo et al., (2009):

$$
P S_{i j}=1-0.5 \sum_{k}\left|p_{i j k}-p_{j k}\right|
$$

$P S_{i j}$ measures the overlap between an individual $i$ 's diet relative composition, $p_{i j k}$, and that of its species $j, p_{j k}$. An average of $P S_{i j}$ across individuals gives $I S_{j}$, the mean individual specialization within species $j$. It allows to calculate $V_{j}=1-I S_{j}$, an intuitive measure of individual diet variation, which varies from 0 (absence of individual diet variation) to 1 (maximum individual diet variation in the population). 
The significance of $V_{j}$ was tested using a nonparametric Monte Carlo simulation to generate replicate diet matrices under the null hypothesis $\left(\mathrm{H}_{0}\right)$ that individuals forage randomly within their species' trophic niche (Araújo et al., 2009; Bolnick et al., 2007). For each species $j$, individual-level replicate null diet matrices were then generated by drawing randomly from species $j$ 's diet the $N_{i j}$ prey items consumed by each individual $i$. This procedure simulates individuals sampling prey stochastically within their species' trophic niche while leaving the species' trophic niche width $B_{j}$ intact. Likewise, the significance of $P S_{j}$ was tested against the null hypothesis that species forage randomly within the set of prey categories available to all species. For each species $j$, the number $N_{j k}$ of items ingested per prey category $k$ was consequently randomized across all prey categories consumed by the fish assemblage to generate species-level replicate null diet matrices. This procedure simulates species choosing prey categories randomly within the set of available ones while keeping the species' trophic niche width $B_{j}$ and individual diet variation $V_{j}$ unchanged. $V_{j, \mathrm{H}_{0}}$ and $P S_{j, \mathrm{H}_{0}}$ were calculated for 1000 individual- and species-level replicate null matrices, respectively, thus providing distributions under the two null hypotheses considered and against which the observed values $V_{j}$ and $P S_{j}$ could be respectively tested.

$B_{j}, P S_{j j^{\prime}}, V_{j}$ and individual-level replicate null matrices were computed with the package "RInSp" (Zaccarelli et al., 2013) and species-level replicate null matrices using the package “ecosim” (Reichert, 2014) of the software R.

\subsubsection{Testing individual state and habitat as sources of individual diet variation}

In order to explore OFT-based sources of individual diet variation, a distance basedredundancy analysis (db-RDA) was performed for each species with the individual diet matrix 
$\mathbf{N}_{j}$ as response matrix and an explanatory matrix containing individual state variables namely total length $(L)$, sex $(S)$,maturity status $(M)$ and community membership $(C)$ taken as a surrogate for habitat and prey availability (Table 2, OFT rows), such that:

$$
\mathbf{N}_{j} \sim L+S+M+C
$$

The distance-based redundancy analysis (db-RDA) is considered as the most robust equivalent of redundancy analysis (RDA) when data imposes the use of Bray-Curtis distance (Legendre and Anderson, 1999). This distance is a semi-metric non-Euclidian and is considered as one of the best option for alleviating the double-zero problem, typical of species abundance data such as in diet matrices. A variation partitioning using db-RDA (Borcard et al., 1992) was performed to assess the contribution of each explanatory variable to individual diet variation (Legendre and Legendre, 2012). These contributions were then tested using partial distance-based redundancy analyses (Legendre and Gallagher 2001) followed by permutation tests, where the variable for which the contribution was estimated was considered as explanatory variable while the other variables as conditions. In order to evaluate the relative contribution of each explanatory variable, only individual contributions were considered whereas the joint contributions of 2 to 4 simultaneous variables were excluded. These analyses were performed using the package "vegan" of the software R.

\subsubsection{Testing predictions from the Niche Variation Hypothesis across species}

The 3 relationships predicted by the NVH were tested using Pearson's correlations between trophic niche metrics across all species: the correlation between trophic niche width and individual diet variation $r\left(B_{j}, V_{j}\right)$ and between trophic niche overlap and both trophic niche width $r\left(B_{j}, P S_{j}\right)$ and individual diet variation $r\left(V_{j}, P S_{j}\right)$. More precisely, each correlation 
between observed metrics was compared to the corresponding correlation under the relevant null hypothesis $\mathrm{H}_{0}$ (Table $2 \mathrm{NVH}$ rows):

(i) $r\left(B_{j}, V_{j}\right)$ was compared to $r\left(B_{j}, \bar{V}_{j, \mathrm{H}_{0}}\right)$ with $\bar{V}_{j, \mathrm{H}_{0}}$ the mean of the null distribution of $V_{j}$. In this case, $\mathrm{H}_{0}$ represents the simple random prey consumption by individuals within their species' niche that will also generate a positive relationship between niche width and individual diet variation due to limited individual diet data (Bolnick et al., 2007);

(ii) $r\left(B_{j}, P S_{j}\right)$ was tested against $r\left(B_{j}, \overline{P S}_{j, \mathrm{H}_{0}}\right)$ with $\overline{P S}_{j, \mathrm{H}_{0}}$ the mean of the null distribution of $P S_{j}$. Here, $\mathrm{H}_{0}$ is the random sampling among all available prey categories by species but within the limits of their trophic niche width results in a mechanistic increase of niche overlap with niche width;

(iii) $r\left(V_{j}, P S_{j}\right)$ was compared to $r\left(V_{j}, \overline{P S}_{j, \mathrm{H}_{0}}\right) . \mathrm{H}_{0}$ is the mechanistic increase of niche overlap with individual diet variation which is also expected from random sampling among all available prey categories by species within the limits of their trophic niche width.

Observed and null correlations were compared using $t$-tests between dependent correlations (i.e. William's test) sharing a common variable: $B_{j}$ for the 2 first ones and $V_{j}$ for the last one (Steiger, 1980). Following Araújo et al. (2009) and Bolnick et al. (2007), the relationships predicted by the NVH were considered as supported if the correlations based on observed metrics are significantly larger $\left(r\left(B_{j}, V_{j}\right)\right)$ or lower $\left(r\left(B_{j}, P S_{j}\right)\right.$ and $\left(r\left(V_{j}, P S_{j}\right)\right)$ than the corresponding correlations under $\mathrm{H}_{0}$. It is indeed important to realize here that the sign of the 
correlations predicted by the $\mathrm{NVH}$ is not to be tested against a correlation equal to 0 but against the correlations under $\mathrm{H}_{0}$ that are precisely non-zero because of stochastic sampling in limited diet data $\left(r\left(B_{j}, \bar{V}_{j, \mathrm{H}_{0}}\right)\right)$ or mechanistic increase $\left(r\left(B_{j}, \overline{P S}_{j, \mathrm{H}_{0}}\right)\right.$ and ( $\left.r\left(V_{j}, \overline{P S}_{j, \mathrm{H}_{0}}\right)\right)$. In other words, it is not the sign of the correlation per se that needs to be tested but rather the sign of the difference between the observed and null correlations. Comparison tests between observed and null correlations were performed with the package "Psych" (Revelle, 2013) of the software R.

2.4.4. Testing predictions from the Niche Variation Hypothesis across and within functional groups of species

Predictions of the NVH were then tested across and within functional groups of species defined according to 3 different approaches. Species were grouped according to either (i) their habitat use and life-history (habitat groups), or (ii) their diet (trophic groups), or (iii) their phylogeny (phylogenetic groups). Habitat use and life history groups were discriminated first by fish position in the water column (pelagic, benthopelagic, demersal and benthic fish). The demersal group was then further subdivided between teleosts and elasmobranchs given their highly different life-histories (short-lived, fast-growing, highly-fecund species for teleosts versus long-lived, slow-growing, poorly-fecund species for elasmobranchs). Final groups are 1) pelagic species (herring, horse mackerel, mackerel, pilchard and sprat), 2) benthopelagic species (cod and whiting), 3) demersal teleosts (seabass, surmullet, red and tub gurnards), 4) demersal elasmobranchs (catshark, skate and smoothhound), and 5) benthic species (plaice and sole). Trophic groups were identified by hierarchical clustering on the species-level diet matrix using the Bray-Curtis distance and the average method (Legendre and Legendre, 
2012). Phylogenetic groups were identified according to species taxonomical position based on Class, Order, Family and Genus (Table A2).

In order to assess whether the $\mathrm{NVH}$ is related to species ecological function, the 3 relationships predicted by the NVH across species, $r\left(B_{j}, V_{j}\right), r\left(B_{j}, P S_{j}\right)$, and $r\left(V_{j}, P S_{j}\right)$, were decomposed into between- and within-group components (Pedhazur, 1997). This decomposition was meant to evaluate whether the NVH predictions were supported between functional groups and between species within functional groups, respectively (see Fig. 1 for the decomposition of the main $\mathrm{NVH}$ predictions into a between- and a within-group correlation). The between- and within-group correlations were compared to the corresponding null correlations as described across all species (see previous section). More precisely, the null correlations $r\left(B_{j}, \bar{V}_{j, \mathrm{H}_{0}}\right), r\left(B_{j}, \overline{P S}_{j, \mathrm{H}_{0}}\right), r\left(V_{j}, \overline{P S}_{j, \mathrm{H}_{0}}\right)$ across species were themselves decomposed into a between- and a within-group correlation that were used as null correlations for their observed counterparts. As the same hypotheses were tested on the same data grouped but in various ways, a Holm correction was applied to P-values to account for multiple tests across the 3 functional group classifications (Holm, 1979; Wright, 1992). Between- and within-group correlation computations and comparison tests between observed and null correlations were performed using the package "Psych" of the software R.

\subsubsection{Sensitivity analysis}

In order to test for the sensitivity of our results to the number of prey categories, all analyses were performed for the classification of prey items into both 41 and 16 categories. The rationale is that it is possible that increasing the number of prey categories considered may allow the detection of higher individual diet variations but, at the same time, may weaken the robustness of results due to the loss of representativity of digestive tract contents. 


\section{Results}

The main text presents and describes results obtained with 16 prey categories whereas results with 41 categories are available as Supplementary Material as they were qualitatively similar. Noticeable differences between results obtained with the two prey classifications are described in the final sub-section 3.5 "Analysis of sensitivity to the number of prey categories".

\subsection{Trophic niche width, overlap and individual diet variation}

Species trophic niche width $B_{j}$ varied by a factor of ca. 5 across species $\left(1.31<B_{j}<6.13\right)$ with a coefficient of variation, $C V$, of 0.43 whereas individual diet variation, $V_{j}$ ( $\left.0.14<V_{j}<0.74\right)$, and average trophic niche overlap, $P S_{j}\left(0.22<P S_{j}<0.46\right)$, varied more moderately with $C V$ s of 0.35 and 0.22 , respectively (Table 1; see also Table A2 for pairwise values of $P S_{j j^{\prime}}$ ). Whatever the species, individual diet variation $V_{j}$ was significantly larger $(\max (p)=0.027)$ than expected under the null hypothesis that individuals forage randomly within their species' trophic niche (see the mean individual diet variation under the null hypothesis $\bar{V}_{j, \mathrm{H}_{0}}$ in Table 1$)$. For 12 out of 16 species, average trophic niche overlap $P S_{j}$ was also significantly larger than expected under the null hypothesis that species feed randomly among all available prey categories according to their trophic niche width (see the mean average trophic niche overlap under the null hypothesis $\overline{P S}_{j, \mathrm{H}_{0}}$ in Table 1). For 2 other species, namely herring and sprat, average trophic overlap was marginally larger than null expectation and for the 2 remaining species, mackerel and plaice, it did not differ significantly from null expectation (Table 1). 


\subsection{Individual state and habitat as sources of individual diet variation}

Across the 16 fish species considered, total length $(L)$ and the community at sampling location $(C)$ were the main factors contributing significantly to diet variation among conspecifics. In contrast, sex $(S)$ and maturity status $(M)$ contributed significantly for only a few species (Table 3). More precisely, sex was significantly related to diets in only 1 species, pilchard, explaining $12.6 \%$ of individual diet variation (Table 3). Maturity status was significantly related to diet in skates and marginally in herring, accounting for only 2.1 and $7.3 \%$ of variation, respectively (Table 3 ). The community at sampling location significantly affected the diets of 6 species and explained from $1.4 \%$ (horse mackerel) to $6.0 \%$ (seabass) of individual diet variations, according to species (Table 3). Total length was significantly linked to individual diet in 7 species and marginally in 3 additional species. It generally explained a larger fraction of individual diet variation ranging from $2.1 \%$ (mackerel) to $26.3 \%$ (herring). Diet was significantly affected by both total length and community in 3 species, namely horse mackerel, smoothhound and surmullet (Table 3).

\subsection{Testing predictions from the Niche Variation Hypothesis across species}

Species trophic niche width significantly increased with the level of individual diet variation ( $r\left(B_{j}, V_{j}\right)>0$; Table 4 and Fig. 3 a, solid circles). In contrast, correlations between species trophic niche width and overlap $r\left(B_{j}, P S_{j}\right)$ and between the level of individual diet variation and trophic niche overlap $r\left(V_{j}, P S_{j}\right)$ were not significantly different from 0 (Table 4 and Fig. $3 \mathrm{~b}$ and c, solid circles).

Most importantly, comparisons between observed and null correlations indicated that $r\left(B_{j}, V_{j}\right)$ did not differ from null expectation whereas $r\left(B_{j}, P S_{j}\right)$ and $r\left(V_{j}, P S_{j}\right)$ were 
significantly smaller than null expectation (Table 4). Paradoxically, this result does not support the NVH for $r\left(B_{j}, V_{j}\right)$ but it complies with its corollary for $r\left(B_{j}, P S_{j}\right)$ and $r\left(V_{j}, P S_{j}\right)$

\subsection{Testing predictions from the Niche Variation Hypothesis across and within functional groups of species}

The composition of functional fish groups based on habitat use and life history (Fig. 4a), clustering of species diet (Fig. 4b) and phylogeny (Fig. 4c) was relatively dissimilar, thus justifying the use of these 3 different approaches in defining functional identity. Whatever the classification, correlation $r\left(B_{j}, V_{j}\right)$ was significantly larger than 0 both between- and withingroups whereas correlations $r\left(B_{j}, P S_{j}\right)$ and $r\left(V_{j}, P S_{j}\right)$ were not significant (except one marginally significant value, Table 5 and Fig. 5 solid squares/circles for between-/withingroup correlations).

Correlations $r\left(B_{j}, P S_{j}\right)$ and $r\left(V_{j}, P S_{j}\right)$ were significantly smaller than null expectation at $5 \%$ (and on 2 occasions at $6.5 \%$ ) risk level both between- and within-groups irrespective of the classification (Table 5 and Fig. 5b-c,e-f,h-i solid squares/circles vs open squares/circles for between-/within-group correlations). In contrast, correlation $r\left(B_{j}, V_{j}\right)$ did not differ from null expectation between- and within-groups whatever the functional classification used (Table 5 and Fig. 5a,b,c solid squares/circles $v s$ open squares/circles for between-/withingroup correlations). This is in agreement with NVH expectations for the first two cases and in disagreement for the last one. It is worth noting that patterns observed between- and withingroups were consistently similar to patterns observed between species whatever the functional 
classification considered, i.e. $r\left(B_{j}, V_{j}\right)$ was in close agreement with null expectation whereas $r\left(B_{j}, P S_{j}\right)$ and $r\left(V_{j}, P S_{j}\right)$ were smaller than null expectation.

\subsection{Sensitivity to the number of prey categories}

The same analyses were performed using 41 prey categories. They revealed qualitatively similar patterns although their amplitude and significance levels varied. Briefly, average niche width $B_{j}$ was almost doubled when increasing the number of prey categories to 41 while average individual diet variation $V_{j}$ increased by $25 \%$ and average trophic niche overlap $P S_{j}$ decreased by $15 \%$ (Table A4 vs. Table 1). Again, individual diet variation $V_{j}$ was significantly larger than null expectation for all species and significance levels of trophic niche overlap $P S_{j}$ increased as these were significantly larger than null expectation for all species but one.

The main sources of individual diet variation, as revealed by variation partitioning, were still total length $(L)$ and the community at sampling location $(C)$ in order of importance, the former being significant or marginally significant for 12 species and the latter for 6 species (Table A6 vs Table 3). Significant variables explained on average higher percentages of variation of individual diet than when using 16 prey categories (Table A6 vs Table 3).

Tests of predictions from the NVH across species were very similar with equivalent patterns (Fig. A2 vs Fig. 3) and significance levels whatever the number of prey categories (Table A7 vs Table 4). Clustering on trophic diet resulted in relatively similar trophic groups although not perfectly equivalent (Fig. A1 vs Fig. 4). Patterns of correlation between niche metrics observed between- and within-functional groups were qualitatively similar when using 16 and 41 prey categories, $r\left(B_{j}, V_{j}\right)$ being close to null expectation, and $r\left(B_{j}, P S_{j}\right)$ and 
$r\left(V_{j}, P S_{j}\right)$ being smaller than null expectation (Fig. A3 vs Fig. 5). However, there was a loss of significance both between- and within-groups when increasing the number of prey categories (Table 5 vs Table A8).

\section{Discussion}

This study aimed to identify diet variation sources within a species assemblage belonging to the same community. We tested several complementary hypotheses suggested by two theoretical frameworks. The first one, Optimal Foraging Theory (OFT), proposes "proximate" sources of individual diet variation, mainly individual state and habitat. The second one, the Niche Variation Hypothesis $(\mathrm{NVH})$, focuses on the "ultimate" sources of individual diet variation, namely selective forces related to the balance between intra- and inter-specific competitions. To the best of our knowledge, this is the first time that the NVH is investigated across species within a given community and across trophic levels (Svanbäck and Bolnick, 2007; Tinker et al., 2012; Woo et al., 2008).

\subsection{Levels of individual diet variation and inter-specific trophic niche overlap}

Whatever the species considered, individual diet variation $V_{j}$ was significantly larger than expected under the null hypothesis of individuals foraging randomly within their species' trophic niche. It suggests that individual diet diversification is ubiquitous within the species of the eastern English Channel fish assemblage. This result also confirms previous findings that fish can feed on a wide diversity of prey items (Bellwood et al., 2006; Bolnick et al., 2003) and exhibit high levels of diet variation between conspecifics (Araùjo et al., 2008; Post et al., 
2008; Svanbäck and Bolnick, 2007; Svanbäck and Persson, 2004). It may be hypothesized that individual specialization in diet is common in marine fishes, especially at upper trophic levels such as the case in this study.

For most species, average trophic niche overlap $P S_{j}$ was also significantly larger than expected under the null hypothesis of each species randomly choosing prey categories among those available to all species. This suggests low trophic resource partitioning between fish species in the eastern English Channel. Trophic niche overlap (or rather its measures) is often viewed as an estimate of inter-specific competition intensity (Schoener, 1974). However, although niche overlap indicates potential inter-specific competition, its intensity also depends on the abundance of consumers and resources (Abrams, 1980). Continental shelf seas such as the eastern English Channel are highly productive areas hosting abundant and diverse low trophic level (primary consumers) resources (Foveau et al., 2013; Kopp et al., 2015). Hence, our results could be interpreted as a consequence of non-limiting trophic resources allowing for the convergence of some species trophic niches without entailing intense inter-specific competition.

\subsection{Sources of individual diet variation within species}

On one hand, individual diet variation was directly related to two "proximate" sources, intraspecific variability in individual state and habitat, as expected from OFT. On the other hand, inter-specific variation in niche width did not appear as an "ultimate" source of individual diet variation, contrary to $\mathrm{NVH}$ expectation. At the intra-specific level, individual diet was indeed significantly related to individual length $L$ and community $C$ at sampling location used, as a proxy for prey availability and habitat. At the inter-specific level, although a positive correlation was observed between species trophic niche width $B_{j}$ and individual diet 
variation $V_{j}$, it did not differ from null expectation, which did not support the main $\mathrm{NVH}$ prediction. Here, it is important to remind that only the comparison with the null correlation matters as it is itself positive because of stochastic sampling in limited diet data (Bolnick et al., 2007). These results highlight clearly "proximate" sources of individual diet variation as expected from OFT. However, the fact that the NVH is not statistically supported does not disqualify "ultimate" sources arising from the balance between intra- and inter-specific competitions (see more explanations in the last paragraph of this section).

According to OFT, individual diet variation may partly result from differences in habitat associated with variation in prey availability and diversity (Estes et al., 2003). In this study, community composition at sampling location explained 1.7 to $6 \%$ of individual diet variation in 6 species. This result reveals that habitat and prey availability may indeed matter for some marine fish species. However, for the other 10 species, the absence of a significant effect of community composition suggests that individuals do not readily change their diets as a function of prey availability. This could reflect a certain degree of food preference or dietary specialization so that individual niche diversification for these species is less influenced by habitat heterogeneity and variation in prey availability, at least at a meso-scale level such as the case in our study.

OFT also generally attributes individual diet variation to phenotypic variation (Bolnick et al., 2003; Svanbäck and Bolnick, 2008). An individual will choose to consume a prey item so as to maximize its fitness benefits. Consequently, its diet is expected not only to depend on prey traits (i.e., ability to avoid predator, chemical or morphological defences, etc.) but also on its own traits (size, morphology, physiological requirements, experience, behaviour, or social status) that may affect predation behaviour. In our study, total length had a major effect on 
individual diet variation and explained from 2 to $29 \%$ of variation in 10 species out of 16 . This result was expected as fish are well known to exhibit ontogenetic niche shifts (Labropoulou et al., 1997; Link and Garrison, 2002; Santic et al., n.d.) and size is known to play an important role in marine fish predator-prey relationships (Scharf et al., 2000). It was therefore likely that total length, as an indicator of ontogeny, would emerge as a factor explaining individual trophic niche variation (Polis, 1984). Physiological requirements may also explain individual trophic niche variation (Svanbäck and Bolnick, 2008). It may be related to an individuals' life-stage, and hence size, but may also depend on maturity and sex (ecological sexual dimorphism besides sexual dimorphism in length). In our study, sex, as well as maturity, showed a significant effect on individual diet variation in only 1 and 2 species, respectively, explaining 2 to $12.6 \%$ of variation. This indicates that some species may exhibit a certain degree of dietary sexual dimorphism, but more studies are needed to assess whether this is a widespread phenomenon in marine fish species.

The NVH stipulates that the expansion of species niche width is accompanied by the increase in variation between individual niches. Our study showed that, within the eastern English Channel marine fish assemblage, species trophic niche width $B_{j}$ is positively related to individual diet variation $V_{j}$. However, this correlation does not differ from null expectation. This reveals that individual diet variation increases as species trophic niche becomes larger which is just as expected when individuals forage randomly in their species' niche. This result does not support the NVH across species in the assemblage but offers other insights in terms of "ultimate" forces related to competition (i.e., selective forces related to the balance between intra- and inter-specific competition). It is worth reminding here that the level of individual diet variation $V_{j}$ obtained was significantly higher than expected for all species 
whatever their trophic niche width $B_{j}$. This is why the regression line of the observed $V_{j}$ according to $B_{j}$ is systematically above (i.e. has a larger intercept than) that of the null data (Fig.3 a). Such high individual diet variation could be a sign of intra-specific competition as it causes individual niche diversification (Svanbäck and Bolnick, 2007, 2005; Van Valen, 1965). The fact that individual diet variation does not increase more than null expectation with species trophic niche width suggests that strong constrains may be imposed by interspecific competition. These constrains should oppose the forces generated by intra-specific competition, thereby limiting species niche width and individual diet variation. Taken together, these two results suggest a subtle competitive balance where intra-specific competition promotes individual niche diversification within the species niche but where inter-specific competition prevents further species niche expansion and constrains the increase of individual niche variation. These results therefore challenge the interpretation of the fact that average trophic niche overlaps $P S_{j}$ can be larger than expected for most species as an evidence of non-limiting trophic resources.

\subsection{Competition and trophic resource partitioning between species}

The hypothesis of non-limiting trophic resources hypothesis is also questioned by the results of the NVH corollary predictions involving species trophic niche overlap. The correlations between species trophic niche overlap $P S_{j}$ and both species trophic niche width $B_{j}$ and individual diet variation $V_{j}$ were significantly lower than expected under the null hypothesis. These results comply with the NVH corollary prediction of a negative relationship between species niche overlap $P S_{j}$ and both trophic niche width $B_{j}$ and individual diet variation $V_{j}$. Null correlations were positive because of a mechanistic positive relationship between the 
expected species trophic niche overlap under random prey sampling among all those available to the fish assemblage and both species trophic niche width and individual diet variation. It is worth reminding here that randomization process across prey categories was done while keeping species niche width and individual diet variation at their observed levels. This result consequently indicates that niche overlap increases less than expected with species niche expansion and individual diet diversification despite a larger niche overlap than null expectation in our findings.

These two results appear contradictory as the first one could be interpreted as a sign of partial partitioning of trophic resources between species whereas the second one suggests nonlimiting resource availability. However, this may also support the idea of a certain degree of food preference of fish species within the assemblage. It is also important to note that the current organization of trophic niches results from primarily on ecological processes related to current competitive pressures and secondly on evolutionary history driven by past competitive pressures (Abrams, 1980; Wiens et al., 2010). It is thus possible to assume that resources are currently not limiting and conditions are allowing species diet to overlap without generating strong inter-specific competition. It is also possible that stronger past inter-specific competitions may have induced character displacement evolution resulting in trophic resources partitioning. The latter could explain why current species niche overlap increases less than expected with species trophic niche width and individual diet variation.

Another aspect that can potentially explain these seemingly contradictory results may be attributed to the time scale of the study. It is important to note that our sampling period of one month (October 2009) can be considered as short-term (see Novak and Tinker, 2015 for the implications of temporal scale on diet specialization indices). It cannot be excluded that the 
intensity of inter-specific competition within the fish assemblage studied here may vary throughout the year, for instance according to seasons. Given that our samples were all caught over a short period in autumn, we may have missed periods of stronger inter-specific competition that could explain trophic resource partitioning in the ecosystem. Testing predictions from various seasons throughout the year would be a way to test this hypothesis. Regarding the non-limiting resources hypothesis, it would also be interesting to test the various NVH-based predictions within communities in a clearly resources limited context, using mesocosm experiments for instance.

\subsection{A functional approach of the Niche Variation Hypothesis}

Using a species assemblage from the same community allowed further testing of the NVH predictions by attempting to identify species' functional identity implications. To the best of our knowledge, a functional approach of the NVH was never investigated before, especially at the assemblage level. Ecological functions performed by species may necessitate varying degrees of ecological traits specialization. We hypothesized that the degree of species ecological specialization is inversely related to ecological niche width and individual niche variation (Devictor et al., 2010). As a consequence, we expect that membership to a functional group would be related to specific trophic niche characteristics. Species performing the same function would then be grouped around the same side of the co-gradient between niche width and individual niche variation. In such case, the NVH should be observed between functional groups. Additionally, species packing within functional groups may exacerbate competition and its effects such that the NVH may also hold between species within functional groups. 
The decomposition of correlations between trophic niche metrics into between- and withingroup components was consistent with observations between species at the assemblage level. Whatever the classification considered, i.e. habitat use and life history, trophic and phylogenetic groups, the correlation between species niche width $B_{j}$ and individual diet variation $V_{j}$ was always in close agreement with null expectation. However, the correlations between trophic niche overlap $P S_{j}$ and both niche width $B_{j}$ and individual diet variation $V_{j}$ were always significantly lower, be it between- or within-groups. The consistency of patterns among analyses suggests that the results observed between species may also apply betweenand within- functional groups. This indicates that the absence of NVH between species at the assemblage level does not directly result to a between- and a within-group component cancelling each other out. Because of the link between species function and niche metrics, one could indeed expect that the NVH is more likely to hold at the between-group level. In such a case, the absence of $\mathrm{NVH}$ between species at the assemblage level may result to the withingroup component situated in the opposite direction and thus cancelling out the between-group one.

Further, it may be hypothesized that the trophic niche organization within the assemblage and the resulting relationships between trophic niche metrics are not more closely related to functional identity than to taxonomic identity. The fact that results are qualitatively unchanged across the different types of functional classification tend to support this hypothesis. However, before drawing general conclusions about the relationship between functional diversity, the NVH and trophic niche organization, further investigations on richer assemblages or communities in terms of functional groups may be necessary. 


\subsection{Implications of the number of prey categories for our conclusions and trophic niche studies}

Our analysis revealed that, besides qualitative agreement, a lower number of prey categories brought more robust results in terms of amplitude and significance levels of the patterns observed. This may originate from a better statistical representativity of individuals' diet when using a lower number of prey categories. It is indeed likely that an increase in the number of prey categories (i.e. the more precise diet description) provides a larger sample size necessary to estimate individual diet variation and other trophic niche metrics. Reducing the number of prey categories to describe diet may increase species diet representativity at lower sample size. On the other hand, our results also show that reducing the precision of diet description by diminishing the number of prey categories results in a decrease in the estimated trophic niche width and individual diet variation while simultaneously increasing trophic niche overlap. These are just as expected and highlights that the loss of precision in diet description due to a reduction of the number of prey categories impairs the estimation of both between-individuals and between-species diet variation. Therefore, we anticipate that there is an intermediate degree of precision in diet description brought about by an intermediate number of preys that is optimal to describe individuals' diet and estimate trophic niche metrics, and that this optimum level may depend both on sample size and on the species studied. Future studies on diet and trophic niche characteristics should then provide more attention on the impact of the number and definition of prey categories as well as on their results and conclusions. 


\section{Conclusion}

Individual diet variation within species of the eastern English Channel fish assemblage appeared directly related to "proximate" sources originating from intra-specific variability in individuals' state and habitat, as suggested by OFT. Inter-specific variation in trophic niche width, primarily expected from the $\mathrm{NVH}$, was not detected as a source of individual diet variation. However, corollary predictions of the NVH about the potential link between species trophic niche overlap, taken as an indicator of inter-specific competition, likewise both species trophic niche width and individual diet variation were supported and revealed partial trophic resource partitioning. These results highlight that relationships between trophic niche overlap and other trophic niche metrics allow drawing ecological conclusions when compared to null models. More specifically, although trophic niche overlap alone cannot estimate interspecific competition intensity, its relationships with species trophic niche width and individual diet variation permitted us to formulate some hypotheses about its potential strength and effects on the organization of trophic niches within an assemblage. In addition, the lack of $\mathrm{NVH}$ prediction support regarding the relationship between individual diet variation and species niche width, does not equate to an uninformative within communities investigation. As shown in this study, the observed relationship did not differ from null expectation. This result allowed us to infer that the balance between intra- and inter-specific competitions may hamper the increase of individual diet variation with species trophic niche width. These results are qualitatively insensitive to the number of prey categories tested (16 and 41) hence providing robust conclusions. These various results were brought by considering the NVH between species from the same community instead of across populations (and thus locations) of the same species. In the seminal work on the Niche Variation Hypothesis (Van Valen, 1965), individual niche variation in trophic morphology 
was related to species ecological niche width. It is indeed expected that mouth gape in fish or beak width in birds, for example, will determine the prey items that these predators can consume. Consequently, variability in diet-related morphological traits between conspecifics may imply diet variability within the population. A complementary approach to this study would therefore be to test whether morphological and behavioural polymorphism are implicated in the relationship between individual niche variation and species niche width across species within a community (Bolnick et al., 2010).

\section{ACKNOWLEDGMENTS}

This work was part of the CHannel integrated Approach for marine Resource Management (CHARM) Phase 3 project within the scope of the INTERREG IVA France-(Channel)England cross-border European Cooperation Program, co-financed by the European Regional Development Fund (ERDF) and managed by the region Haute Normandie. M.C. was also supported by a doctoral fellowship from the Institut Français de Recherche pour l'Exploitation de la Mer (IFREMER). We thank Manuel Rouquette and Mickaël Baheux for their crucial help in the laboratory. We would like to thank two anonymous reviewers whose comments helped us to greatly improve a previous version of this manuscript.

\section{REFERENCES}

Abrams, P., 1980. Some Comments on Measuring Niche Overlap. Ecology 61, 44-49. doi:10.2307/1937153

Albert, C.H., de Bello, F., Boulangeat, I., Pellet, G., Lavorel, S., Thuiller, W., 2012. On the importance of intraspecific variability for the quantification of functional diversity. Oikos 121, 116-126. doi:10.1111/j.1600-0706.2011.19672.x

Araùjo, M.S., Bolnick, D.I., Layman, C.A., 2011. The ecological causes of individual specialisation. Ecol. Lett. 14, 948-958. doi:10.1111/j.1461-0248.2011.01662.x 
Araújo, M.S., Bolnick, D.I., Martinelli, L.A., Giaretta, A.A., Dos Reis, S.F., 2009. Individuallevel diet variation in four species of Brazilian frogs. J. Anim. Ecol. 78, 848-856. doi:10.1111/j.1365-2656.2009.01546.x

Araùjo, M.S., Guimarães Jr, P.R., Svanbäck, R., Pinheiro, A., Guimarães, P., dos Reis, S.F., Bolnick, D.I., 2008. Network analysis reveals contrasting effects of intraspecific competition on individual VS. population diets. Ecology 89, 1981-1993. doi:10.1890/07-0630.1

Bellwood, D.R., Wainwright, P.C., Fulton, C.J., Hoey, A.S., 2006. Functional versatility supports coral reef biodiversity. Proc. R. Soc. B 273, 101-107.

Bolnick, D.I., Amarasekare, P., Araùjo, M.S., Bürger, R., Levine, J.M., Novak, M., Rudolf, V.H.W., Schreiber, S.J., Urban, M.C., Vasseur, D.A., 2011. Why intraspecific trait variation matters in community ecology. Trends Ecol. Evol. 26, 183-192. doi:10.1016/j.tree.2011.01.009

Bolnick, D.I., Ingram, T., Stutz, W.E., Snowberg, L.K., Lau, O.L., Paull, J.S., 2010. Ecological release from interspecific competition leads to decoupled changes in population and individual niche width. Proc. R. Soc. B Biol. Sci. 277, 1789-1797. doi:10.1098/rspb.2010.0018

Bolnick, D.I., Svanbäck, R., Araùjo, M.S., Persson, L., 2007. Comparative support for the niche variation hypothesis that more generalized populations also are more heterogeneous. PNAS 104, 10075-10079.

Bolnick, D.I., Svanbäck, R., Fordyce, J.A., Yang, L.H., Davis, J.M., Hulsey, C.D., Forister, M.L., 2003. The ecology of individuals: incidence and implications of individual specialization. Am. Nat. 161, 1-28. doi:10.1086/343878

Bolnick, D.I., Yang, L.H., Fordyce, J.A., Davis, J.M., Svanbäck, R., 2002. Measuring individual-level resource specialization. Ecology 83, 2936-2941. doi:10.1890/00129658(2002)083[2936:MILRS]2.0.CO;2

Borcard, D., Legendre, P, Drapeau P., 1992. Partialling out the spatial component of ecological variation. Ecology 73, 145-1055.

Cianciaruso, M.V., Batalha, M.A., Gaston, K.J., Petchey, O.L., 2009. Including intraspecific variability in functional diversity. Ecology 90, 81-89. doi:10.1890/07-1864.1

Devictor, V., Clavel, J., Julliard, R., Lavergne, S., Mouillot, D., Thuiller, W., Venail, P., Villéger, S., Mouquet, N., 2010. Defining and measuring ecological specialization. J. Appl. Ecol. 47, 15-25.

Estes, J.., Riedman, M.L., Staedler, M.M., Tinker, M.T., Lyon, B.E., 2003. Individual variation in prey selection by sea otters: patterns, causes and implications. J. Anim. Ecol. 72, 144-155.

Foveau, A., Desroy, N., Dauvin, J.C., Dewarumez, J.M., 2013. Distribution patterns in the benthic diversity of the eastern English Channel. Mar. Ecol. Prog. Ser. 479, 115-126. doi:10.3354/meps 10128

Galeotti, P., Rubolini, D., 2004. The niche variation hypothesis and the evolution of colour polymorphism in birds: a comparative study of owls, nightjars and raptors. Biol. J. Linn. Soc. 82, 237-248. doi:10.1111/j.1095-8312.2004.00355.x

Holm, S., 1979. A Simple Sequentially Rejective Multiple Test Procedure. Scand. J. Stat. 6, 65-70.

Kopp, D., Lefebvre, S., Cachera, M., Villanueva, M.C., Ernande, B., 2015. Reorganization of a marine trophic network along an inshore-offshore gradient due to stronger pelagicbenthic coupling in coastal areas. Prog. Oceanogr. 130, 157-171.

doi:10.1016/j.pocean.2014.11.001 
Labropoulou, M., Machias, A., Tsimenides, N., Eleftheriou, A., 1997. Feeding habits and ontogenic diet shift of the striped red mullet, Mullus surmuletus Linnaeus, 1758. Fish. Res. 31, 257-267. doi:10.1016/S0165-7836(97)00017-9

Legendre, P., Anderson, M.J., 1999. Distance-based redundancy analysis: testing multispecies responses in multifactorial ecological experiments. Ecol. Monogr. 69, 1-24. doi:10.1890/0012-9615(1999)069[0001:DBRATM]2.0.CO;2

Legendre, P., Gallagher, E.D. 2001. Ecologically meaningful transformations for ordination of species data. Oecologia 129, 271-28. doi:10.1007/s004420100716.

Legendre, P., Legendre, L., 2012. Numerical ecology, third english edition, ELSEVIER. ed.

Levin, R., 1968. Evolution in changing environments, Princetown University Press. ed. Princetown, New Jersey, USA.

Link, J.S., Garrison, L.P., 2002. Trophic ecology of Atlantic cod Gadus morhua on the northeast US continental shelf. Mar. Ecol. Prog. Ser. 227, 109-123. doi:10.3354/meps227109

Martin, C.S., Meaden, G.J., Vaz, S., Dupuis, L., Lauria, V., Ernande, B., Dauvin, J.C., Spilmont, N., Dewarumez, J.M., Foveau, A., Garcia, C., Carpentier, A., 2010. Channel Habitat Atlas for Marine Resource Management - an aid to managing a resourcestressed marine area., in: Ocean Globe. ESRI Press Academic, Redlands, California, US.

Meiri, S., Dayan, T., Simberloff, D., 2005. Variability and sexual size dimorphism in carnivores: testing the Niche Variation Hypothesis. Ecology 86, 1432-1440. doi:10.1890/04-1503

Novak, M., Tinker, M.T., 2015. Timescales alter the inferred strength and temporal consistency of intraspecific diet specialization. Oecologia 178, 61-74. doi:10.1007/s00442-014-3213-2

Oksanen, J., Blanchet, F.G., Kindt, R., Legendre, P., Minchin, P.R., O’Hara, R.B., Simpson, G.L., Solymos, P., Stevens, M.H.H., Wagner, H., 2015. vegan: Community Ecology Package. R package version 2.2-1 [WWW Document]. HttpCRANR-Proj.

Pachepsky, E., Bown, J.L., Eberst, A., Bausenwein, U., Millard, P., Squire, G.R., Crawford, J.W., 2007. Consequences of intraspecific variation for the structure and function of ecological communities Part 2: Linking diversity and function. Ecol. Model. 207, 227285. doi:10.1016/j.ecolmodel.2007.05.005

Pedhazur, E.J., 1997. Multiple regression in behavioral research: explanation and prediction, 3rd edition., Fort Worth. ed. Harcourt Brace, TX.

Petchey, O.L., Gaston, K.J., 2006. Functional diversity: back to basics and looking forward. Ecol. Lett. 9, 741-758. doi:10.1111/j.1461-0248.2006.00924.x

Polis, G.A., 1984. Age structure component of niche width and intraspecific resource partitioning: can age groups function as ecological species? Am. Nat. 123, 541-564.

Post, D.M., Palkovacs, E.P., Schielke, E.G., Dodson, S.I., 2008. Intraspecific variation in a predator affects community structure and cascading trophic interactions. Ecology 89, 2019-2032.

R Core Team, 2015. R: A language and environment for statistical computing. R Foundation for Statistical Computing, Vienna, Austria.

Reichert, P., 2014. ecosim: Toolbox for Aquatic Ecosystem Modeling. R package version 1.2. [WWW Document]. URL http://CRAN.R-project.org/package=ecosim

Revelle, W., 2013. psych: Procedures for Personality and Psychological Research, Northwestern University, Evanston, Illinois, USA [WWW Document]. URL http://CRAN.R-project.org/package=psych Version $=1.4 .2$ 
Santic, M., Jardas, I., Pallaoro, A., n.d. Feeding habits of horse mackerel, Trachurus trachurus (Linneaus, 1758), from the central Adriatic Sea. J. Appl. Ichthyol. 21, 125-130. doi:10.1111/j.1439-0426.2004.00603.x

Scharf, F.S., Juanes, F., Rountree, R.A., 2000. Predator size- prey size relationships of marine fish predators: interspecific variation and effects of ontogeny and body size on trophic-niche breadth. Mar. Ecol. Prog. Ser. 208, 229-248. doi:10.3354/meps208229

Schluter, D., 1996. Ecological causes of adaptive radiation. Am. Nat. 148, S40-S64.

Schoener, T.W., 1974. Some Methods for Calculating Competition Coefficients from Resource-Utilization Spectra. Am. Nat. 108, 332-340.

Schoener, T.W., 1971. Theory of feeding strategies. Annu. Rev. Ecol. Syst. 2, 369-404.

Schoener, T.W., 1968. The Anolis Lizards of Bimini: Resource Partitioning in a Complex Fauna. Ecology 49, 704-726. doi:10.2307/1935534

Somero, G.N., Soulé, M., 1974. Genetic variation in marine fishes as a test of the nichevariation hypothesis. Nature 249, 670-672. doi:10.1038/249670a0

Steiger, J.H., 1980. Tests for comparing elements of a correlation matrix. Psychol. Bull. 87, 245-251. doi:10.1037/0033-2909.87.2.245

Svanbäck, R., Bolnick, D.I., 2008. Food specialization, in: Encyclopedia of Ecology. Sven Erik Jorgensen and Brian D. Fath, Oxford, pp. 1636-1642.

Svanbäck, R., Bolnick, D.I., 2007. Intraspecific competition drives increased resource use diversity within a natural population. Proc. R. Soc. B 274, 839-844. doi:10.1098/rspb.2006.0198

Svanbäck, R., Bolnick, D.I., 2005. Intraspecific competition affects the strength of individual specialization: an optimal diet theory method. Evol. Ecol. Res. 7, 993-1012.

Svanbäck, R., Eklöv, P., Fransson, R., Holmgren, K., 2008. Intraspecific competition drives multiple species resource polymorphism in fish communities. Oikos 117, 114-124. doi:10.1111/j.2007.0030-1299.16267.x

Svanbäck, R., Persson, L., 2004. Individual diet specialization, niche width and population dynamics: implications for trophic polymorphism. J. Anim. Ecol. 73, 973-982.

Tinker, M.T., Guimarães Jr, P.R., Novak, M., Marquitti, F.M.D., Bodkin, J.L., Staedler, M., Bentall, G., Estes, J., 2012. Structure and mechanism of diet specialisation: testing models of individual variation in resource use with sea otters. Ecol. Lett. 15, 475-483.

Van Valen, L., 1965. Morphological variation and width of ecological niche. Am. Nat. 99, 377-390.

Werner, E.E., Hall, D.J., 1974. Optimal foraging and the size selection of prey by the Bluegill Sunfish (Lepomis Macrochirus). Ecology 55, 1042-1052.

Wiens, J.J., Ackerly, D.D., Allen, A.P., Anacker, B.L., Buckley, L.B., Cornell, H.V., Damschen, E.I., Jonathan Davies, T., Grytnes, J.-A., Harrison, S.P., Hawkins, B.A., Holt, R.D., McCain, C.M., Stephens, P.R., 2010. Niche conservatism as an emerging principle in ecology and conservation biology. Ecol. Lett. 13, 1310-1324. doi:10.1111/j.1461-0248.2010.01515.x

Woo, K.J., Elliott, K.H., Davidson, M., Gaston, A.J., Davoren, G.K., 2008. Individual specialization in diet by a generalist marine predator reflects specialization in foraging behavior. J. Anim. Ecol. 77, 1082-1091.

Wright, S.P., 1992. Adjusted P-Values for Simultaneous Inference. Biometrics 48, 10051013. doi:10.2307/2532694

Zaccarelli, N., Bolnick, D.I., Mancinelli, G., 2013. RInSp: an r package for the analysis of individual specialization in resource use. Methods Ecol. Evol. n/a-n/a. doi:10.1111/2041-210X.12079 
Table 1: Trophic niche metrics of the 16 species studied using 16 prey categories. For each species, the following quantities are given: number of individuals $n$, trophic niche width estimated as the Levin's index $B_{j}$, individual level variation in diet $V_{j}$ together with the mean of its null distribution $\bar{V}_{j, \mathrm{H}_{0}}$, and average trophic niche overlap $P S_{j}$ together with the mean of its null distribution $\overline{P S}_{j, \mathrm{H}_{0}}$. The significance level of $V_{j}$ and $P S_{j}$ determined by comparison with their distribution under their respective null hypotheses is also given $\left({ }^{n s}\right.$ : non-significant, $\left.\dagger: \mathrm{p} \leq 0.1,{ }^{*}: \mathrm{p} \leq 0.05,{ }^{* *}: \mathrm{p} \leq 0.01,{ }^{* * *}: \mathrm{p} \leq 0.001\right)$.

\begin{tabular}{|c|c|c|c|c|c|c|c|}
\hline Common name & $\begin{array}{l}\text { Scientific } \\
\text { name }\end{array}$ & $n$ & $B_{j}$ & $V_{j}$ & $\bar{V}_{j, \mathrm{H}_{0}}$ & $P S_{j}$ & $\overline{P S}_{j, \mathrm{H}_{0}}$ \\
\hline Catshark & $\begin{array}{l}\text { Scyliorhinus } \\
\text { canicula }\end{array}$ & 38 & 3.56 & $0.35^{* * *}$ & 0.27 & $0.42^{* * * *}$ & 0.25 \\
\hline Cod & $\begin{array}{l}\text { Gadus } \\
\text { morhua }\end{array}$ & & 3.33 & $0.49^{* * * *}$ & 0.37 & $0.43^{* * *}$ & 0.25 \\
\hline Herring & $\begin{array}{l}\text { Clupea } \\
\text { harengus }\end{array}$ & & 1.33 & $0.21^{* * * *}$ & 0.12 & $0.22 \dagger$ & 0.16 \\
\hline Horse mackerel & $\begin{array}{l}\text { Trachurus } \\
\text { trachurus }\end{array}$ & 89 & 4.57 & $0.54^{* * *}$ & 0.34 & $0.46^{* * *}$ & 0.27 \\
\hline Mackerel & $\begin{array}{l}\text { Scomber } \\
\text { scombrus }\end{array}$ & 53 & 5.34 & $0.74^{* * *}$ & 0.58 & $0.32^{n s}$ & 0.29 \\
\hline Pilchard & $\begin{array}{l}\text { Sardina } \\
\text { pilchardus }\end{array}$ & 29 & 1.86 & $0.41^{* * * *}$ & 0.20 & $0.26^{*}$ & 0.18 \\
\hline Plaice & $\begin{array}{l}\text { Pleuronectes } \\
\text { platessa }\end{array}$ & 71 & 5.02 & $0.64^{* * *}$ & 0.53 & $0.22^{n s}$ & 0.25 \\
\hline Red gurnard & $\begin{array}{l}\text { Chelidonichthys } \\
\text { cuculus }\end{array}$ & 41 & 2.66 & $0.42^{* * *}$ & 0.32 & $0.40^{* * *}$ & 0.22 \\
\hline Seabass & $\begin{array}{l}\text { Dicentrarchus } \\
\text { labrax }\end{array}$ & 81 & 5.43 & $0.67^{* * *}$ & 0.54 & $0.44^{* * *}$ & 0.28 \\
\hline Skate & $\begin{array}{l}\text { Raja } \\
\text { clavata }\end{array}$ & 63 & 2.54 & $0.39^{* * *}$ & 0.27 & $0.41^{* * *}$ & 0.22 \\
\hline
\end{tabular}




\begin{tabular}{llcccccc} 
Smoothhound & $\begin{array}{l}\text { Mustelus } \\
\text { asterias }\end{array}$ & 48 & 1.31 & $0.14^{*}$ & 0.11 & $0.33^{* * *}$ & 0.15 \\
Sole & $\begin{array}{l}\text { Solea } \\
\text { solea }\end{array}$ & 46 & 5.00 & $0.57^{* * *}$ & 0.37 & $0.34^{*}$ & 0.26 \\
Sprat & $\begin{array}{l}\text { Sprattus } \\
\text { sprattus }\end{array}$ & 24 & 1.77 & $0.37^{* *}$ & 0.24 & $0.25 \dagger$ & 0.18 \\
Surmullet & $\begin{array}{l}\text { Mullus } \\
\text { surmuletus }\end{array}$ & 94 & 4.28 & $0.50^{* * *}$ & 0.32 & $0.36^{* *}$ & 0.26 \\
Tub gurnard & $\begin{array}{l}\text { Chelidonichthys } \\
\text { lucerna }\end{array}$ & 48 & 3.93 & $0.58^{* * *}$ & 0.45 & $0.36^{* *}$ & 0.24 \\
Whiting & $\begin{array}{l}\text { Merlangius } \\
\text { merlangus }\end{array}$ & 54 & 6.13 & $0.69^{* * *}$ & 0.60 & $0.39^{* * *}$ & 0.30 \\
\hline
\end{tabular}


Table 2: Conceptual theories and related predictions about the sources of individual diet variation, corresponding statistical tests and biological scale, potential results and their interpretation.

\begin{tabular}{|c|c|c|c|c|c|}
\hline Theory & Prediction & Test & Scale & Potential Result & Interpretation \\
\hline OFT & $\begin{array}{l}\text { Individual diet } \\
\text { depends on prey } \\
\text { availability and/or } \\
\text { habitat }\end{array}$ & $\begin{array}{l}\text { RDA on individual diet matrix: } \\
\text { Community, } C \text {, effect }\end{array}$ & Species & $C$ is (not) significant & $\begin{array}{l}\text { Prey availability and/or } \\
\text { habitat is (not) a source of } \\
\text { individual diet variation }\end{array}$ \\
\hline \multirow[t]{2}{*}{ OFT } & \multirow[t]{2}{*}{$\begin{array}{l}\text { Individual diet } \\
\text { depends on phenotypic } \\
\text { variation }\end{array}$} & $\begin{array}{l}\text { RDA on individual diet matrix: } \\
\text { Length, } L \text {, effect }\end{array}$ & Species & $L$ is (not) significant & $\begin{array}{l}\text { Ontogenetic diet shift is (not) } \\
\text { a source of individual diet } \\
\text { variation }\end{array}$ \\
\hline & & $\begin{array}{l}\text { Maturity, } M \text {, and } \\
\text { Sex, } S \text {, effects }\end{array}$ & Species & $\begin{array}{l}M \text { and/or } S \text { are/is (not) } \\
\text { significant }\end{array}$ & $\begin{array}{l}\text { Variation in physiological } \\
\text { requirements is (not) a source } \\
\text { of individual diet variation }\end{array}$ \\
\hline \multirow[t]{3}{*}{$\mathrm{NVH}$} & \multirow[t]{3}{*}{$\begin{array}{l}\text { Positive relationship } \\
\text { between species } \\
\text { trophic niche width, } \\
B_{j} \text {, and individual } \\
\text { diet variation, } V_{j}\end{array}$} & \multirow[t]{3}{*}{$\begin{array}{l}r\left(B_{j}, V_{j}\right)=r\left(B_{j}, \bar{V}_{j, \mathrm{H}_{0}}\right) \\
\text { Two-tailed test of equality of two } \\
\text { dependent correlations sharing a } \\
\text { common variable }\end{array}$} & \multirow[t]{3}{*}{$\begin{array}{l}\text { Community } \\
\text { Between } \\
\text { functional } \\
\text { groups } \\
\text { Within } \\
\text { functional } \\
\text { groups }\end{array}$} & $\begin{array}{l}\mathrm{H}_{0} \text { rejected: } \\
r\left(B_{j}, V_{j}\right)>r\left(B_{j}, \bar{V}_{j, \mathrm{H}_{0}}\right)\end{array}$ & $\begin{array}{l}\text { Niche Variation Hypothesis } \\
\text { supported, i.e. individual diet } \\
\text { variation increases with } \\
\text { species trophic niche width } \\
\text { are more than expected under } \\
\mathrm{H}_{0} \text { as } r\left(B_{j}, \bar{V}_{j, \mathrm{H}_{0}}\right)>0\end{array}$ \\
\hline & & & & $\mathrm{H}_{0}$ accepted & $\begin{array}{l}\text { Individuals consume prey } \\
\text { randomly within the limits of } \\
\text { their species niche }\end{array}$ \\
\hline & & & & $\begin{array}{l}\mathrm{H}_{0} \text { rejected: } \\
r\left(B_{j}, V_{j}\right)<r\left(B_{j}, \bar{V}_{j, \mathrm{H}_{0}}\right)\end{array}$ & $\begin{array}{l}\text { Individual diet variation } \\
\text { increases with species } \\
\text { trophic niche width less than } \\
\text { expected under } \mathrm{H}_{0}\end{array}$ \\
\hline $\mathrm{NVH}$ & $\begin{array}{l}\text { Negative relationship } \\
\text { between trophic niche }\end{array}$ & $r\left(B_{j}, P S_{j}\right)=r\left(B_{j}, \overline{P S}_{j, \mathrm{H}_{0}}\right)$ & $\begin{array}{l}\text { Community } \\
\text { Between }\end{array}$ & $\mathrm{H}_{0}$ rejected: & $\begin{array}{l}\text { Niche Variation Hypothesis } \\
\text { supported, i.e. trophic niche }\end{array}$ \\
\hline
\end{tabular}




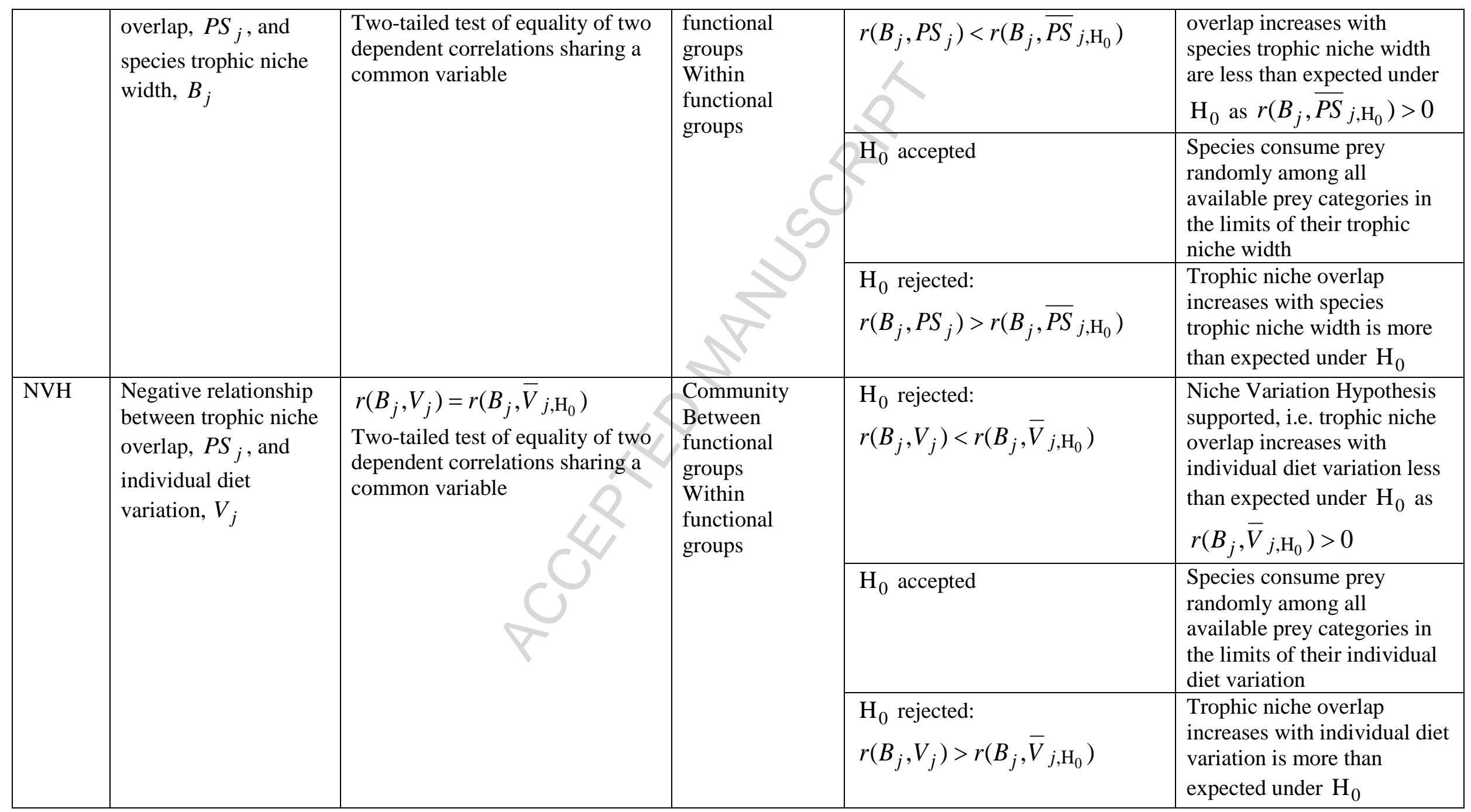


Table 3: Individual state and habitat as sources of individual level diet variation using 16 prey categories. The results of the db-RDA variation partitioning on the individual-level diet matrix are presented for each fish species. The percentage of variation (multivariate adjusted $\mathrm{R}^{2}$ ) explained by each explanatory variable (columns) is given together with its significance level $\left({ }^{n s}\right.$ : non-significant, $\left.\dagger: \mathrm{p} \leq 0.1,{ }^{*}: \mathrm{p} \leq 0.05,{ }^{* *}: \mathrm{p} \leq 0.01,{ }^{* * *}: \mathrm{p} \leq 0.001\right)$.

\begin{tabular}{|c|c|c|c|c|}
\hline Species & Length $(L)$ & $\operatorname{Sex}(S)$ & Maturity $(M)$ & Community $(C$ ) \\
\hline Catshark & $-1.0^{n s}$ & $-0.1^{n s}$ & $2.0^{n s}$ & $1.7^{*}$ \\
\hline Cod & $3.9^{*}$ & $-1.2^{n s}$ & & $0.0^{n s}$ \\
\hline Herring & $26.3^{* *}$ & $0.2^{n s}$ & $7.3 \dagger$ & $-0.7^{n s}$ \\
\hline Horse mackerel & $6.4^{* * *}$ & $0.0^{n s}$ & $-0.1^{n s}$ & $1.4^{*}$ \\
\hline Mackerel & $2.1 \dagger$ & $-0.9^{n s}$ & $-1.5^{n s}$ & $-0.3^{n s}$ \\
\hline Pilchard & $-1.0^{n s}$ & & $-2.1^{n s}$ & $0.0^{n s}$ \\
\hline Plaice & $-0.7^{n s}$ & & $-0.2^{n s}$ & $1.9^{*}$ \\
\hline Red gurnard & $2.4 \dagger$ & $-1.8^{n s}$ & $1.0^{n s}$ & $2.1^{n s}$ \\
\hline Seabass & $-0.1^{n s}$ & $-0.2^{n s}$ & $0.0^{n s}$ & $6.0^{* * *}$ \\
\hline Skate & $11.7^{* * *}$ & $-0.1^{n s}$ & $2.1^{*}$ & $-0.6^{n s}$ \\
\hline Smoothhound & $3.4 \dagger$ & $-1.2^{n s}$ & $-0.8^{n s}$ & $5.7^{*}$ \\
\hline Sole & $6.4^{* *}$ & $1.1^{n s}$ & $0.4^{n s}$ & $-0.4^{n s}$ \\
\hline Sprat & $29.1^{* *}$ & $1.4^{n s}$ & $6.4^{n s}$ & $0.0^{n s}$ \\
\hline Surmullet & $3.0^{* * *}$ & $-0.1^{n s}$ & $-0.2^{n s}$ & $4.7^{* * *}$ \\
\hline Tub gurnard & $-1.0^{n s}$ & $-0.4^{n s}$ & $0.1^{n s}$ & $-1.1^{n s}$ \\
\hline Whiting & $0.0^{n s}$ & $-1.1^{n s}$ & $-0.4^{n s}$ & $-1.1^{n s}$ \\
\hline
\end{tabular}


Table 4: Tests of correlations between trophic niche metrics predicted by the Niche Variation Hypothesis across species using 16 prey categories. Correlations (value) and associated standard error (SE) are given for observed and null data. Student statistics (t), degrees of freedom (df) and associated P-values (P) are given for the tests of observed correlations being different from 0 (Observed) and from the corresponding null correlations (Comparison). The latter accounts for the fact that observed and null correlations are dependent as they share a common variable, $B_{j}$ for the 2 first ones and $V_{j}$ for the last one. Significant P-values are indicated in bold.

\begin{tabular}{|c|c|c|c|c|c|c|c|c|}
\hline \multirow[b]{2}{*}{ Correlation } & \multicolumn{3}{|c|}{ Observed } & \multicolumn{2}{|l|}{ Null } & \multicolumn{3}{|c|}{ Comparison } \\
\hline & value & $\mathrm{SE}$ & df $\quad P$ & value & $\mathrm{SE}$ & $\mathrm{t}$ & df & $\mathrm{P}$ \\
\hline$r\left(B_{j}, V_{j}\right)$ & 0.92 & 0.11 & $<0.001$ & 0.91 & 0.11 & 0.08 & 13 & 0.936 \\
\hline$r\left(B_{j}, P S_{j}\right)$ & 0.36 & 0.25 & 0.167 & 0.94 & 0.09 & -6.95 & 13 & $<0.001$ \\
\hline$r\left(V_{j}, P S_{j}\right)$ & 0.22 & $0.26 \bigcirc 0.85$ & 0.407 & 0.88 & 0.13 & -6.68 & 13 & $<0.001$ \\
\hline
\end{tabular}


Table 5: Tests of correlations between trophic niche metrics predicted by the Niche Variation Hypothesis between and within groups of species using 16 prey categories. Correlations (value) and associated standard error (SE) are given for both observed and null data. Student statistic (t), degrees of freedom (df) and associated P-values (P) are given for the tests of observed correlations being different from 0 (Observed) and from the corresponding null correlations (Comparison). The latter accounts for the fact that observed and null correlations are dependent as they share a common variable, $B_{j}$ for the 2 first ones and $V_{j}$ for the last one. Tests are performed between (Between-group correlations) and within (Within-group correlations) group of species defined according to 3 different approaches: either trait, or trophic, or phylogenetic groups. Significant (or marginally significant at $\mathrm{P}<0.1$ ) $\mathrm{P}$-values are indicated in bold.

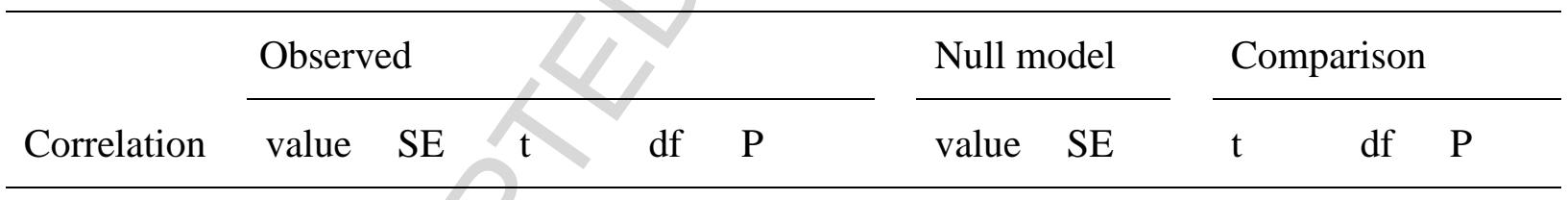

Trait groups

Between-group correlations

$\begin{array}{lllllllllll}r\left(B_{j}, V_{j}\right) & 0.93 & 0.21 & 4.47 & 3 & \mathbf{0 . 0 2 1} & 0.98 & 0.12 & -1.05 & 2 & 1.000 \\ r\left(B_{j}, P S_{j}\right) & 0.07 & 0.58 & 0.11 & 3 & 0.958 & 0.94 & 0.19 & -4.99 & 2 & \mathbf{0 . 0 3 8} \\ r\left(V_{j}, P S_{j}\right) & -0.11 & 0.57 & -0.20 & 3 & 1.000 & 0.87 & 0.28 & -5.41 & 2 & \mathbf{0 . 0 6 5}\end{array}$

Within-group correlations

$\begin{array}{lllllllllll}r\left(B_{j}, V_{j}\right) & 0.91 & 0.11 & 8.21 & 9 & <\mathbf{0 . 0 0 1} & 0.88 & 0.13 & 0.75 & 8 & 1.000 \\ r\left(B_{j}, P S_{j}\right) & 0.56 & 0.22 & 2.52 & 9 & \mathbf{0 . 0 9 8} & 0.95 & 0.09 & -4.11 & 8 & \mathbf{0 . 0 1 0} \\ r\left(V_{j}, P S_{j}\right) & 0.47 & 0.24 & 2.00 & 9 & 0.231 & 0.90 & 0.12 & -3.65 & 8 & \mathbf{0 . 0 1 3}\end{array}$

Trophic groups 
Between-group correlations

$\begin{array}{lllllllllll}r\left(B_{j}, V_{j}\right) & 0.96 & 0.14 & 6.77 & 4 & \mathbf{0 . 0 0 5} & 0.93 & 0.18 & 0.67 & 3 & 1.000 \\ r\left(B_{j}, P S_{j}\right) & 0.41 & 0.46 & 0.91 & 4 & 0.958 & 0.97 & 0.13 & -5.69 & 3 & \mathbf{0 . 0 2 1} \\ r\left(V_{j}, P S_{j}\right) & 0.29 & 0.48 & 0.60 & 4 & 1.000 & 0.89 & 0.23 & -3.53 & 3 & \mathbf{0 . 0 6 5}\end{array}$

Within-group correlations

$\begin{array}{llllllllllr}r\left(B_{j}, V_{j}\right) & 0.86 & 0.14 & 6.19 & 8 & \mathbf{0 . 0 0 1} & 0.87 & 0.13 & -0.17 & 7 & 1.000 \\ r\left(B_{j}, P S_{j}\right) & 0.17 & 0.26 & 0.65 & 8 & 0.532 & 0.88 & 0.13 & -3.78 & 7 & \mathbf{0 . 0 1 4} \\ r\left(V_{j}, P S_{j}\right) & 0.06 & 0.27 & 0.24 & 8 & 0.814 & 0.86 & 0.14 & -4.40 & 7 & \mathbf{0 . 0 0 9}\end{array}$

Phylogenetic groups

Between-group correlations

$\begin{array}{lllllllllll}r\left(B_{j}, V_{j}\right) & 0.95 & 0.15 & 6.34 & 4 & \mathbf{0 . 0 0 7} & 0.96 & 0.14 & -0.23 & 3 & 1.000 \\ r\left(B_{j}, P S_{j}\right) & 0.48 & 0.44 & 1.08 & 4 & 1.000 & 0.97 & 0.12 & -6.90 & 3 & \mathbf{0 . 0 1 9} \\ r\left(V_{j}, P S_{j}\right) & 0.34 & 0.47 & 0.72 & 4 & 1.000 & 0.91 & 0.20 & -5.43 & 3 & \mathbf{0 . 0 3 7}\end{array}$

Within-group correlations

\begin{tabular}{lllllllllll}
$r\left(B_{j}, V_{j}\right)$ & 0.83 & 0.15 & 5.50 & 8 & $\mathbf{0 . 0 0 1}$ & 0.82 & 0.15 & 0.06 & 7 & 1.000 \\
$r\left(B_{j}, P S_{j}\right)$ & 0.04 & 0.27 & 0.15 & 8 & 1.000 & 0.82 & 0.15 & -2.97 & 7 & $\mathbf{0 . 0 2 1}$ \\
$r\left(V_{j}, P S_{j}\right)$ & -0.05 & 0.27 & -0.19 & 8 & 1.000 & 0.80 & 0.16 & -3.20 & 7 & $\mathbf{0 . 0 1 5}$ \\
\hline
\end{tabular}


Figure 1: Decomposition of the across-species Niche Variation Hypothesis into a between- and a within-functional group component. a) NVH (black regression line) across species (solid circles) pertaining to 3 functional groups (shades of gray). b) NVH (black regression line) between functional groups represented by the mean niche width and mean individual niche variation of their species (solid squares). The dashed line is the acrossspecies NVH. The NVH may (or may not) apply between functional groups. If it does, the location of a species along the gradient predicted by the $\mathrm{NVH}$ will depend on its functional identity (membership to a functional group). c) NVH (regression lines in shades of gray) within functional groups (solid circles in shades of gray). The dashed line and the dotted line are the across-species and the between-functional group NVH, respectively. The NVH may (or may not) apply between species within functional groups.

Figure 2: Map of the area covered by the Channel Ground Fish Survey with sampling points (trawls' location). Only trawls where fishes used in this study were caught are represented.

Figure 3: Correlations between trophic niche metrics predicted by the Niche Variation Hypothesis across species using 16 prey categories. a) correlation between species trophic niche width $B_{j}$ and individual diet variation $V_{j}$. b) correlation between $B_{j}$ and species trophic niche similarity $P S_{j}$. c) correlation between $V_{j}$ and $P S_{j}$. Solid circles (and black line) are observed data and related regression respectively, open circles (and dotted line) indicate data under the null hypothesis and related regression respectively.

Figure 4: Functional grouping of the studied species according to a) habitat use and life history, b) clustering of species diet using 16 prey categories and c) phylogenetic relationships as inferred from taxonomy 
Figure 5: Correlations between trophic niche metrics predicted by the Niche Variation Hypothesis between and within group of species using 16 prey categories. a, d, g,) correlation between species trophic niche width $B_{j}$ and individual diet variation $V_{j} . \mathrm{b}, \mathrm{e}, \mathrm{h}$ ) correlation between $B_{j}$ and species trophic niche similarity $\left.P S_{j}, \mathrm{c}, \mathrm{f}, \mathrm{i}\right)$ correlation between $V_{j}$ and $P S_{j}$. Solid circles (and black line) are observed data and related regression respectively, open circles (and dotted line) indicate data under the null hypothesis and related regression respectively. Niche metrics for each group (calculated as the average metric values across species affiliated to this group), their standard deviations and the related regression are depicted by solid squares, vertical-horizontal bars and the black line, respectively. Niche metrics for each group (calculated as the average metric values again), their standard deviations and the related regression under the null model are depicted by open squares, vertical-horizontal bars and the dotted line respectively. 
Across species NVH

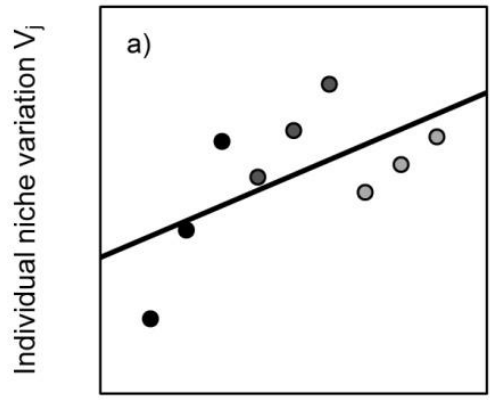

Niche width $B_{j}$
Between functional groups NVH

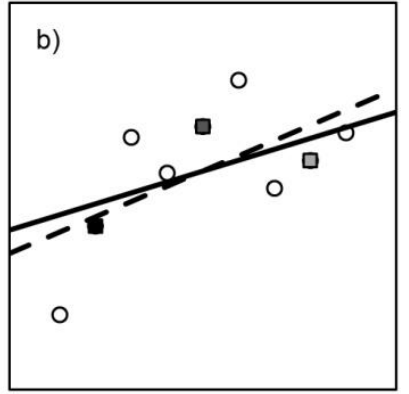

Niche width $B$
Within functional groups NVH

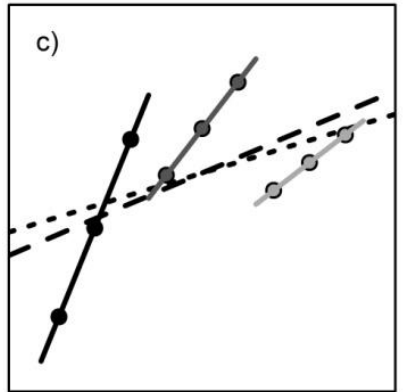

Niche width $B$

Figure 1 


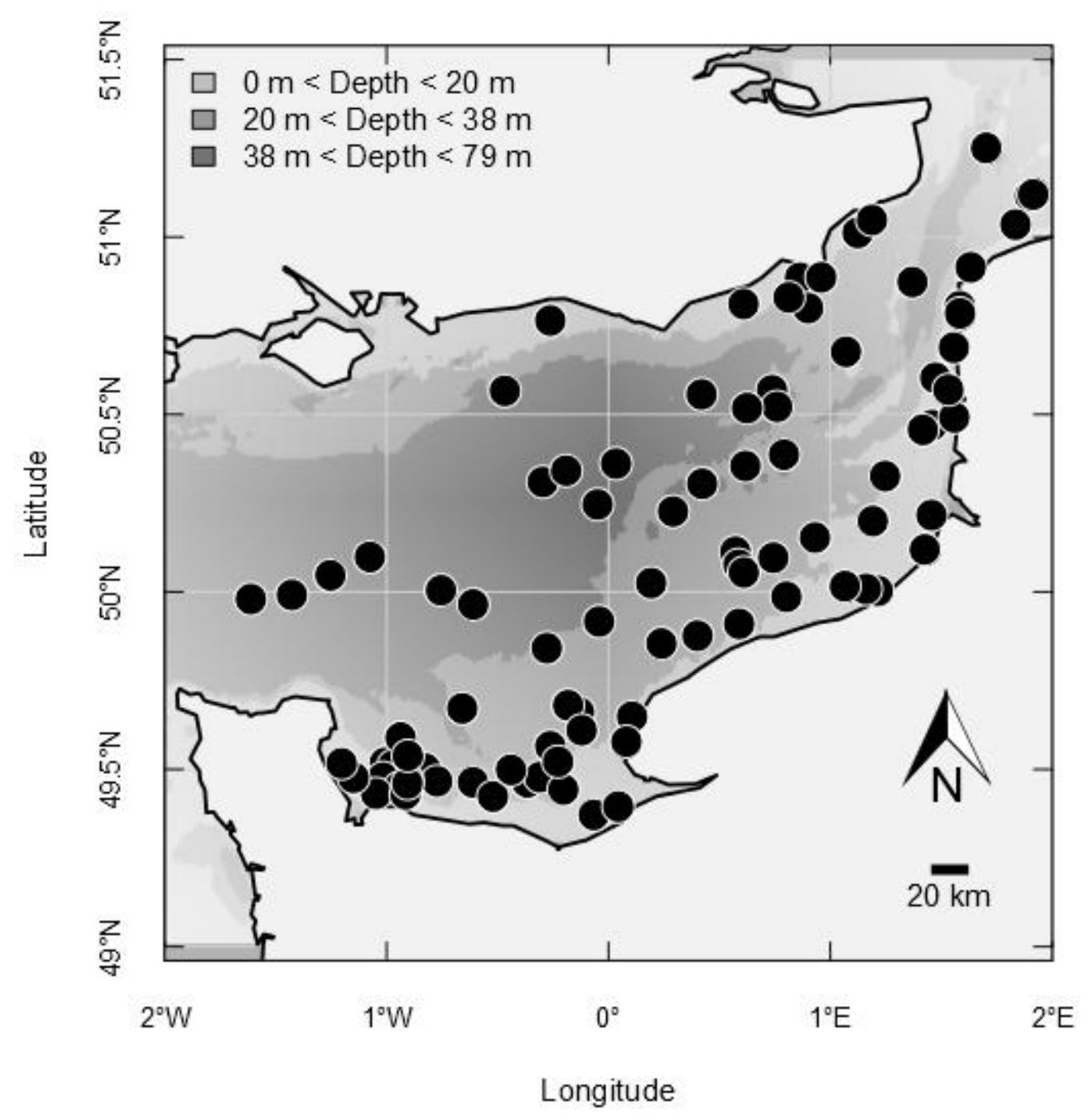

Figure 2 

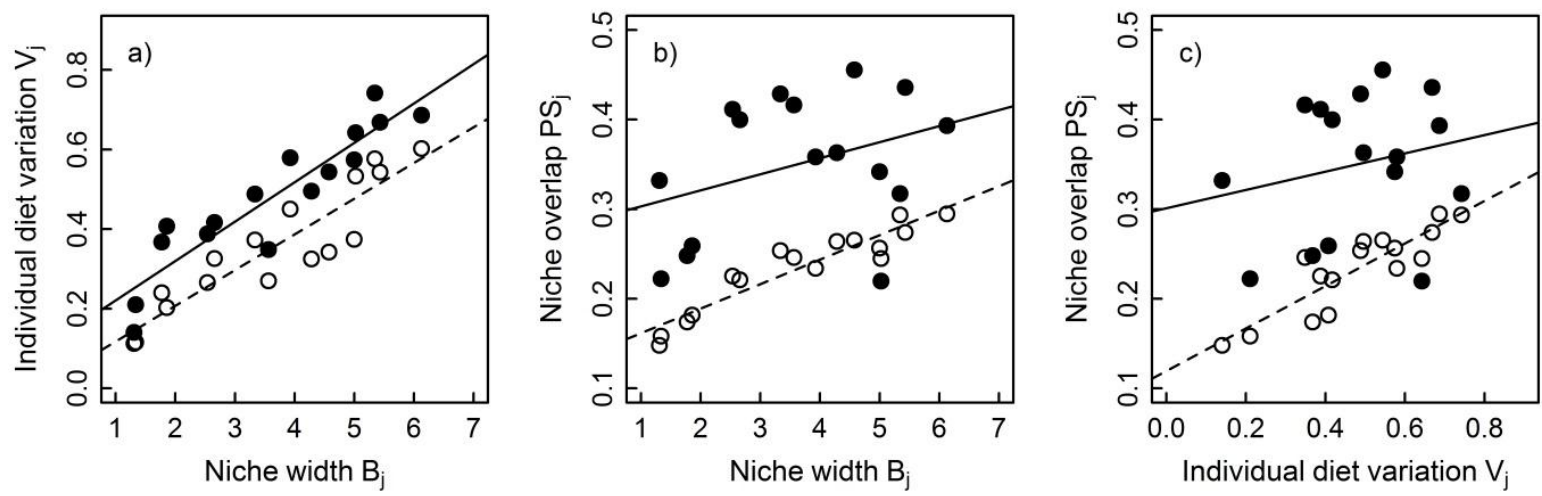

Figure 3 
a) Habitat/life history groups

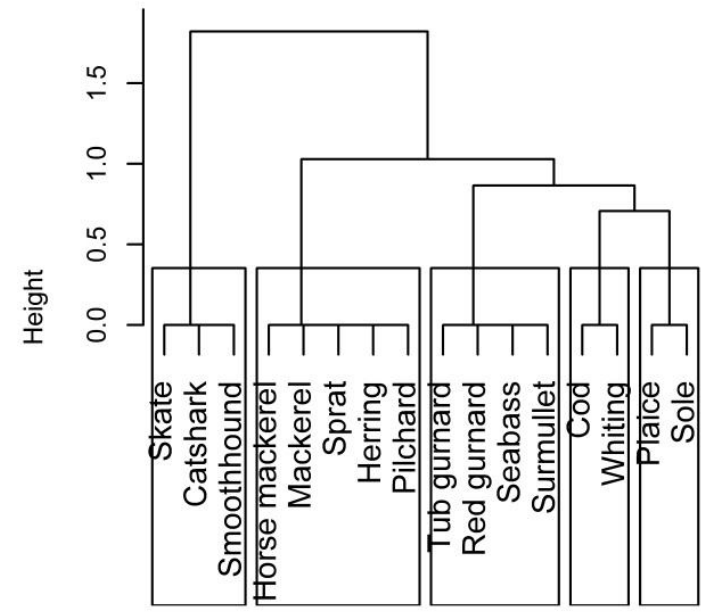

b) Trophic groups

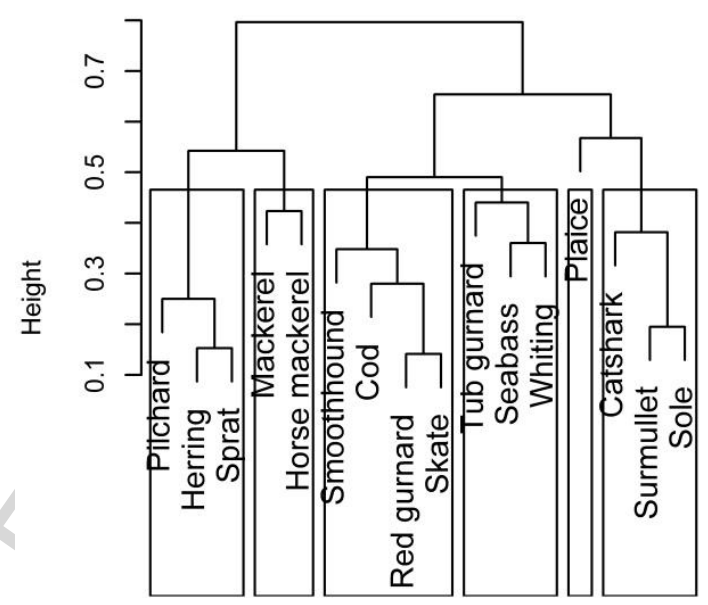

c) Phylogenetic groups

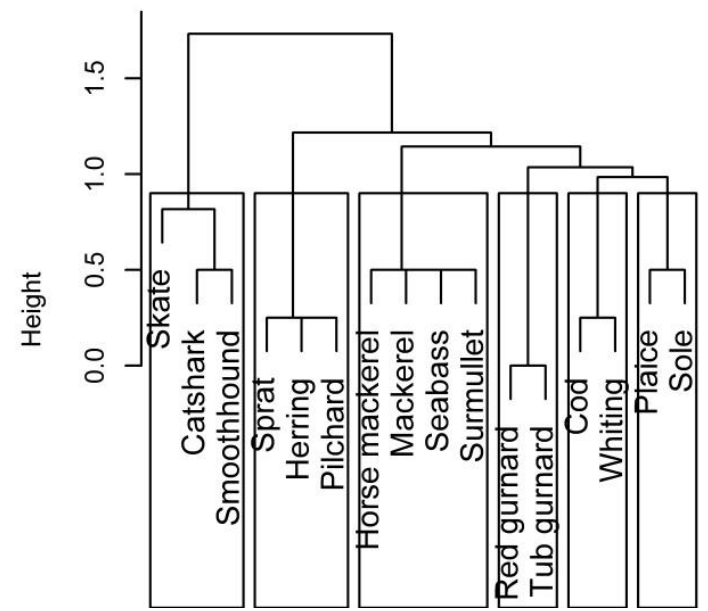

Figure 4 

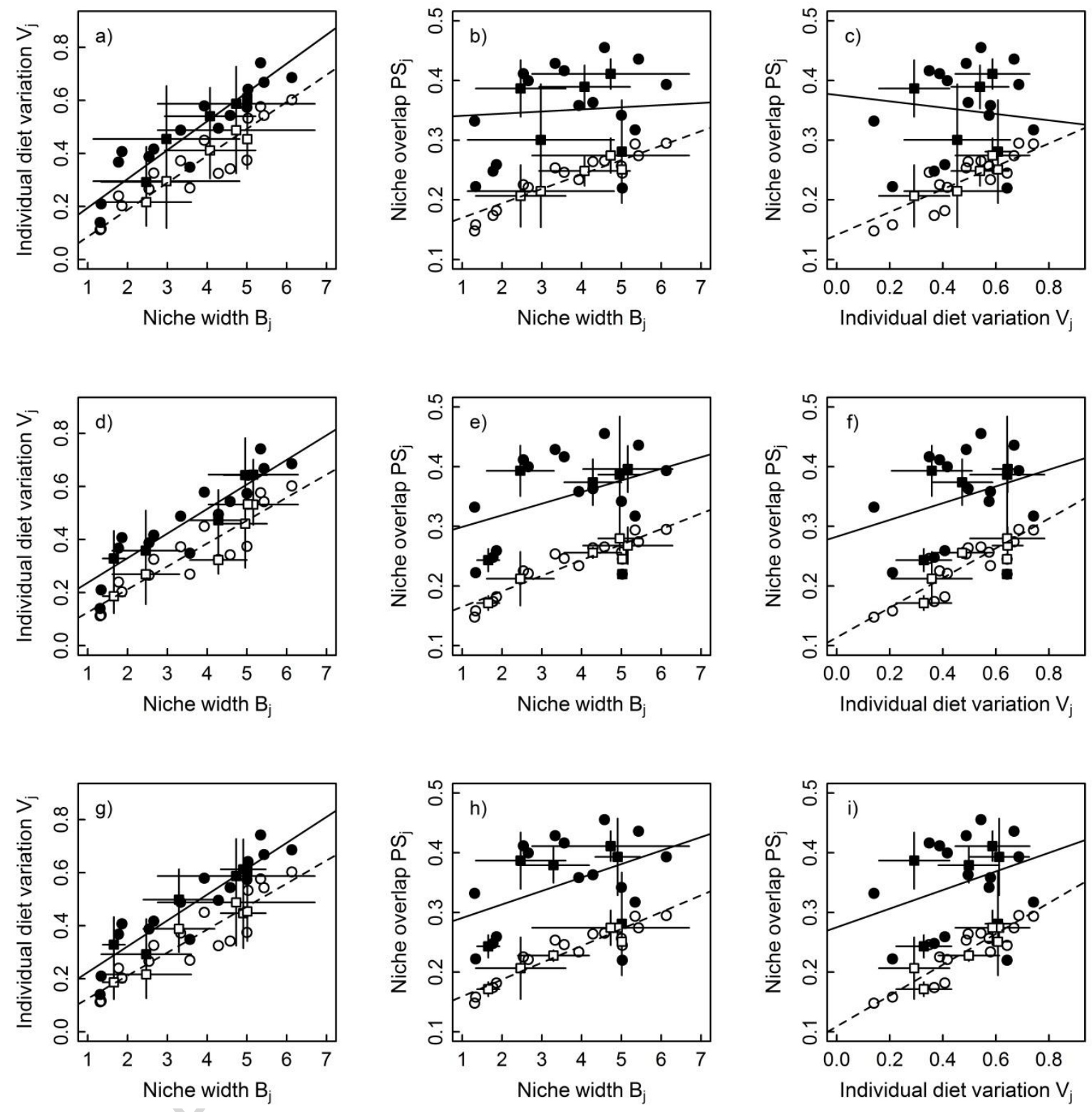

Figure 5 


\section{Supplementary material}

Table A1: Taxonomy of identified preys in digestive tract contents. Preys were grouped first into 41 categories based on a combination of taxonomy and function, and then further grouped into 16 categories for sensitivity test purpose.

See excel file 
Table A2: Taxonomy of the 16 fish species studied

\begin{tabular}{lllll} 
Class & Order & Family & Genus & Species \\
\hline Elasmobranchii & Carcharhiniformes & Scyliorhinidae & Scyliorhinus & Scyliorhinus canicula \\
Elasmobranchii & Carcharhiniformes & Triakidae & Mustelus & Mustelus asterias \\
Elasmobranchii & Rajiformes & Rajidae & Raja & Raja clavata \\
Actinopteri & Clupeiformes & Clupeidae & Clupea & Clupea harengus \\
Actinopteri & Clupeiformes & Clupeidae & Sardina & Sardina pilchardus \\
Actinopteri & Clupeiformes & Clupeidae & Sprattus & Sprattus sprattus \\
Actinopteri & Gadiformes & Gadidae & Gadus & Gadus morhua \\
Actinopteri & Gadiformes & Gadidae & Merlangius & Merlangius merlangus \\
Actinopteri & Perciformes & Moronidae & Dicentrarchus & Dicentrarchus labrax \\
Actinopteri & Perciformes & Mullidae & Mullus & Mullus surmuletus \\
Actinopteri & Perciformes & Scombridae & Scomber & Scomber scombrus \\
Actinopteri & Perciformes & Carangidae & Trachurus & Trachurus trachurus \\
Actinopteri & Pleuronectiformes & Pleuronectidae & Pleuronectes & Pleuronectes platessa \\
Actinopteri & Pleuronectiformes & Soleidae & Solea & Solea solea \\
Actinopteri & Scorpaeniformes & Triglidae & Chelidonichthys & Chelidonichthys cuculus \\
Actinopteri & Scorpaeniformes & Triglidae & Chelidonichthys & Chelidonichthys lucerna \\
\hline
\end{tabular}


Table A3: Pairwise trophic niche similarity estimated with Proportional Similarity indices $\left(P S_{j j^{\prime}}\right)$ between each pair of species using 16 prey categories.

\begin{tabular}{|c|c|c|c|c|c|c|c|c|c|c|c|c|c|c|c|c|}
\hline & Catshark & Cod & Herring & $\begin{array}{l}\text { Horse } \\
\text { mackerel }\end{array}$ & Mackerel & Pilchard & Plaice & $\begin{array}{l}\text { Red } \\
\text { gurnard }\end{array}$ & Seabass & Skate & $\begin{array}{l}\text { Smooth } \\
\text { hound }\end{array}$ & Sole & Sprat & $\begin{array}{l}\text { Surmulle } \\
t\end{array}$ & $\begin{array}{l}\text { Tub } \\
\text { gurnard }\end{array}$ & Whiting \\
\hline Catshark & - & - & - & - & - & - & - & - & & - & - & - & - & - & - & - \\
\hline Cod & 0.34 & - & - & - & - & - & - & - & - & - & - & - & - & - & - & - \\
\hline Herring & 0.08 & 0.05 & - & - & - & - & - & & - & - & - & - & - & - & - & - \\
\hline Horse mackerel & 0.42 & 0.27 & 0.45 & - & - & - & - & - & - & - & - & - & - & - & - & - \\
\hline Mackerel & 0.21 & 0.25 & 0.40 & 0.56 & - & - & & - & - & - & - & - & - & - & - & - \\
\hline Pilchard & 0.08 & 0.13 & 0.74 & 0.44 & 0.51 & - & & - & - & - & - & - & - & - & - & - \\
\hline Plaice & 0.37 & 0.29 & 0.04 & 0.15 & 0.18 & 0.01 & & - & - & - & - & - & - & - & - & - \\
\hline Red gurnard & 0.45 & 0.38 & 0.06 & 0.44 & 0.18 & 0.10 & 0.10 & - & - & - & - & - & - & - & - & - \\
\hline Seabass & 0.37 & 0.60 & 0.07 & 0.32 & 0.36 & 0.24 & 0.29 & 0.34 & - & - & - & - & - & - & - & - \\
\hline Skate & 0.50 & 0.46 & 0.06 & 0.39 & 0.18 & .08 & 0.17 & 0.57 & 0.42 & - & - & - & - & - & - & - \\
\hline Smoothhound & 0.50 & 0.53 & 0.04 & 0.39 & 0.14 & 0.05 & 0.15 & 0.59 & 0.41 & 0.60 & - & - & - & - & - & - \\
\hline Sole & 0.59 & 0.34 & 0.06 & 0.22 & 0.19 & 0.05 & 0.47 & 0.23 & 0.35 & 0.26 & 0.25 & - & - & - & - & - \\
\hline Sprat & 0.07 & 0.06 & 0.84 & 0.46 & 0.40 & 0.76 & 0.03 & 0.07 & 0.07 & 0.06 & 0.03 & 0.05 & - & - & - & - \\
\hline Surmullet & 0.54 & 0.21 & 0.07 & 0.34 & 0.22 & 0.07 & 0.36 & 0.26 & 0.33 & 0.27 & 0.29 & 0.66 & 0.06 & - & - & - \\
\hline Tub gurnard & 0.39 & 0.40 & 0.04 & 0.41 & 0.20 & 0.13 & 0.13 & 0.60 & 0.44 & 0.51 & 0.37 & 0.23 & 0.06 & 0.22 & - & - \\
\hline Whiting & 0.40 & 0.34 & 0.13 & 0.42 & 0.47 & 0.36 & 0.21 & 0.44 & 0.50 & 0.45 & 0.30 & 0.28 & 0.14 & 0.35 & 0.43 & - \\
\hline
\end{tabular}


Table A4: Trophic niche metrics of the 16 species studied using 41 prey categories. For each species, the following quantities are given: number of individuals $n$, trophic niche width estimated as the Levin's index $B_{j}$, individual level variation in diet $V_{j}$ together with the mean of its null distribution $\bar{V}_{j, \mathrm{H}_{0}}$, and average trophic niche overlap $P S_{j}$ together with the mean of its null distribution $\overline{P S}_{j, \mathrm{H}_{0}}$. The significance level of $V_{j}$ and $P S_{j}$ determined by comparison with their distribution under their respective null hypotheses is also given $\left({ }^{n s}\right.$ : non-significant, $\left.\dagger: p \leq 0.1,{ }^{*}: \mathrm{p} \leq 0.05,{ }^{* *}: \mathrm{p} \leq 0.01,{ }^{* * *}: \mathrm{p} \leq 0.001\right)$.

\begin{tabular}{|c|c|c|c|c|c|c|c|}
\hline Common name & $\begin{array}{l}\text { Scientific } \\
\text { name }\end{array}$ & $n$ & $B_{j}$ & $V_{j}$ & $\bar{V}_{j, \mathrm{H}_{0}}$ & $P S_{j}$ & $\overline{P S}_{j, \mathrm{H}_{0}}$ \\
\hline Catshark & $\begin{array}{l}\text { Scyliorhinus } \\
\text { canicula }\end{array}$ & 38 & 7.20 & $0.49^{* * * *}$ & 0.40 & $0.35^{* * *}$ & 0.20 \\
\hline Cod & $\begin{array}{l}\text { Gadus } \\
\text { morhua }\end{array}$ & & 12.35 & $0.74^{* * * *}$ & 0.56 & $0.31^{* *}$ & 0.22 \\
\hline Herring & $\begin{array}{l}\text { Clupea } \\
\text { harengu. }\end{array}$ & & 1.34 & $0.21^{* * * *}$ & 0.13 & $0.21^{* *}$ & 0.10 \\
\hline Horse mackerel & $\begin{array}{l}\text { Trachurus } \\
\text { trachurus }\end{array}$ & 89 & 5.16 & $0.59^{* * * *}$ & 0.39 & $0.38^{* * * *}$ & 0.18 \\
\hline Mackerel & $\begin{array}{l}\text { Scomber } \\
\text { scombrus }\end{array}$ & 53 & 5.37 & $0.75^{* * * *}$ & 0.58 & $0.30^{* * *}$ & 0.19 \\
\hline Pilchard & $\begin{array}{l}\text { Sardina } \\
\text { pilchardus }\end{array}$ & 29 & 1.86 & $0.41^{* * * *}$ & 0.20 & $0.25^{* * *}$ & 0.10 \\
\hline Plaice & $\begin{array}{l}\text { Pleuronectes } \\
\text { platessa }\end{array}$ & 71 & 8.59 & $0.77^{* * * *}$ & 0.65 & $0.20^{n s}$ & 0.18 \\
\hline Red gurnard & $\begin{array}{l}\text { Chelidonichthys } \\
\text { cuculus }\end{array}$ & 41 & 5.65 & $0.59^{* * * *}$ & 0.48 & $0.32^{* * * *}$ & 0.19 \\
\hline Seabass & $\begin{array}{l}\text { Dicentrarchus } \\
\text { labrax }\end{array}$ & 81 & 12.18 & $0.80^{* * * *}$ & 0.70 & $0.34^{* * *}$ & 0.23 \\
\hline Skate & $\begin{array}{l}\text { Raja } \\
\text { clavata }\end{array}$ & 63 & 7.22 & $0.62^{* * * *}$ & 0.44 & $0.33^{* * * *}$ & 0.20 \\
\hline
\end{tabular}




\begin{tabular}{|c|c|c|c|c|c|c|c|}
\hline Smoothhound & $\begin{array}{l}\text { Mustelus } \\
\text { asterias }\end{array}$ & 48 & 5.48 & $0.50^{* * * *}$ & 0.32 & $0.31^{* * * *}$ & 0.20 \\
\hline Sole & $\begin{array}{l}\text { Solea } \\
\text { solea }\end{array}$ & 46 & 7.51 & $0.68^{* * * *}$ & 0.48 & $0.28^{* *}$ & 0.20 \\
\hline Sprat & $\begin{array}{l}\text { Sprattus } \\
\text { sprattus }\end{array}$ & 24 & 1.80 & $0.38^{* *}$ & 0.26 & $0.21^{* *}$ & 0.11 \\
\hline Surmullet & $\begin{array}{l}\text { Mullus } \\
\text { surmuletus }\end{array}$ & 94 & 6.92 & & 0.44 & $0.28^{* *}$ & 0.20 \\
\hline Tub gurnard & $\begin{array}{l}\text { Chelidonichthys } \\
\text { lucerna }\end{array}$ & 48 & 6.90 & & 0.57 & $0.30^{* * *}$ & 0.18 \\
\hline Whiting & $\begin{array}{l}\text { Merlangius } \\
\text { merlangus }\end{array}$ & 54 & 7.02 & & 0.64 & $0.35^{* * *}$ & 0.19 \\
\hline
\end{tabular}


Table A5: Pairwise trophic niche similarity estimated with Proportional Similarity indices $\left(P S_{j j^{\prime}}\right)$ between each pair of species using 41 prey categories.

\begin{tabular}{|c|c|c|c|c|c|c|c|c|c|c|c|c|c|c|c|c|}
\hline & Catshark & Cod & Herring & $\begin{array}{l}\text { Horse } \\
\text { mackerel }\end{array}$ & Mackerel & Pilchard & Plaice & $\begin{array}{l}\text { Red } \\
\text { gurnard }\end{array}$ & Seab & Skate & Smoothhound & Sole & Sprat & Surmullet & $\begin{array}{l}\text { Tub } \\
\text { gurnard }\end{array}$ & Whiting \\
\hline Catshark & - & - & - & - & - & - & - & - & - & - & - & - & - & - & - & - \\
\hline Cod & 0.34 & - & - & - & - & - & - & - & & - & - & - & - & - & - & - \\
\hline Herring & 0.08 & 0.05 & - & - & - & - & - & & - & - & - & - & - & - & - & - \\
\hline Horse mackerel & 0.42 & 0.27 & 0.45 & - & - & - & - & 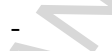 & - & - & - & - & - & - & - & - \\
\hline Mackerel & 0.21 & 0.25 & 0.40 & 0.56 & - & - & - & 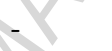 & - & - & - & - & - & - & - & - \\
\hline Pilchard & 0.08 & 0.13 & 0.74 & 0.44 & 0.51 & - & 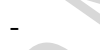 & - & - & - & - & - & - & - & - & - \\
\hline Plaice & 0.37 & 0.29 & 0.04 & 0.15 & 0.18 & 0.01 & & - & - & - & - & - & - & - & - & - \\
\hline Red gurnard & 0.45 & 0.38 & 0.06 & 0.44 & 0.18 & 0.10 & 0.10 & - & - & - & - & - & - & - & - & - \\
\hline Seabass & 0.37 & 0.60 & 0.07 & 0.32 & 0.36 & 0.24 & 0.29 & 0.34 & - & - & - & - & - & - & - & - \\
\hline Skate & 0.50 & 0.46 & 0.06 & 0.39 & 0.18 & 0.08 & 0.17 & 0.57 & 0.42 & - & - & - & - & - & - & - \\
\hline Smoothhound & 0.50 & 0.53 & 0.04 & 0.39 & 0.14 & 0.05 & 0.15 & 0.59 & 0.41 & 0.60 & - & - & - & - & - & - \\
\hline Sole & 0.59 & 0.34 & 0.06 & 0.22 & 0.19 & 0.05 & 0.47 & 0.23 & 0.35 & 0.26 & 0.25 & - & - & - & - & - \\
\hline Sprat & 0.07 & 0.06 & 0.84 & 0.46 & 0.40 & 0.76 & 0.03 & 0.07 & 0.07 & 0.06 & 0.03 & 0.05 & - & - & - & - \\
\hline Surmullet & 0.54 & 0.21 & 0.07 & 0.34 & 0.22 & 0.07 & 0.36 & 0.26 & 0.33 & 0.27 & 0.29 & 0.66 & 0.06 & - & - & - \\
\hline Tub gurnard & 0.39 & 0.40 & 0.04 & 0.41 & 0.20 & 0.13 & 0.13 & 0.60 & 0.44 & 0.51 & 0.37 & 0.23 & 0.06 & 0.22 & - & - \\
\hline Whiting & 0.40 & 0.34 & 0.13 & 0.42 & 0.47 & 0.36 & 0.21 & 0.44 & 0.50 & 0.45 & 0.30 & 0.28 & 0.14 & 0.35 & 0.43 & - \\
\hline
\end{tabular}


Table A6: Individual state and habitat as sources of individual level diet variation using 41 prey categories. The results of the db-RDA variation partitioning on the individual-level diet matrix are presented for each fish species. The percentage of variation (multivariate adjusted $\mathrm{R}^{2}$ ) explained by each explanatory variable (columns) is given together with its significance level $\left({ }^{n s}\right.$ : non-significant, $\left.\dagger: \mathrm{p} \leq 0.1,{ }^{*}: \mathrm{p} \leq 0.05,{ }^{* *}: \mathrm{p} \leq 0.01,{ }^{* * *}: \mathrm{p} \leq 0.001\right)$.

\begin{tabular}{|c|c|c|c|c|}
\hline Species & Length $(L)$ & $\operatorname{Sex}(S)$ & Maturity $(M)$ & Community $(C)$ \\
\hline Catshark & $5.5^{* *}$ & $3.2^{*}$ & $4.0^{* *}$ & $7.6^{* * *}$ \\
\hline Cod & $6.6^{* * *}$ & $-0.2^{n s}$ & $0.3^{n s}$ & $0.0^{n s}$ \\
\hline Herring & $25.4^{* *}$ & $0.5^{n s}$ & $7.7^{*}$ & $-0.2^{n s}$ \\
\hline Horse mackerel & $5.6^{* * *}$ & $0.2^{n s}$ & $-0.2^{n s}$ & $1.7^{*}$ \\
\hline Mackerel & $2.3 \dagger$ & $-1.0^{n s}$ & $-1.3^{n s}$ & $-0.3^{n s}$ \\
\hline Pilchard & $-1.0^{n s}$ & & $-2.1^{n s}$ & $0.0^{n s}$ \\
\hline Plaice & $0.4^{n s}$ & & $0.7^{n s}$ & $2.3^{*}$ \\
\hline Red gurnard & $2.3 \dagger$ & $-1.7^{n s}$ & $3.2^{*}$ & $2.0 \dagger$ \\
\hline Seabass & $0.2^{n s}$ & $0.0^{n s}$ & $0.3^{n s}$ & $2.8^{* * *}$ \\
\hline Skate & $7.3^{* * *}$ & $-0.1^{n s}$ & $0.5^{n s}$ & $-0.6^{n s}$ \\
\hline Smoothhound & $2.2^{*}$ & $-0.3^{n s}$ & $-0.6^{n s}$ & $0.4^{n s}$ \\
\hline Sole & $4.6^{* *}$ & $-0.2^{n s}$ & $0.2^{n s}$ & $0.3^{n s}$ \\
\hline Sprat & $23.1^{* *}$ & $0.7^{n s}$ & $4.7^{n s}$ & $0.0^{n s}$ \\
\hline Surmullet & $1.5^{*}$ & $-0.2^{n s}$ & $0.1^{n s}$ & $3.5^{* * *}$ \\
\hline Tub gurnard & $2.6^{*}$ & $-0.2^{n s}$ & $-0.4^{n s}$ & $-0.9^{n s}$ \\
\hline Whiting & $0.6^{n s}$ & $-0.5^{n s}$ & $-0.4^{n s}$ & $-0.9^{n s}$ \\
\hline
\end{tabular}


Table A7: Tests of correlations between trophic niche metrics predicted by the Niche Variation Hypothesis across species using 41 prey categories. Correlations (value) and associated standard error (SE) are given for both observed and null data. Student statistics (t), degrees of freedom (df) and associated $P$-values $(\mathrm{P})$ are given for the tests of observed correlations being different from 0 (Observed) and from the corresponding null correlations (Comparison). The latter accounts for the fact that observed and null correlations are dependent as they share a common variable, $B_{j}$ for the 2 first ones and $V_{j}$ for the last one. Significant P-values are indicated in bold.

\begin{tabular}{|c|c|c|c|c|c|c|c|c|c|}
\hline \multirow[b]{2}{*}{ Correlation } & \multicolumn{4}{|c|}{ Observed } & \multicolumn{2}{|l|}{ Null } & \multicolumn{3}{|c|}{ Comparison } \\
\hline & value & SE & $\mathrm{t}$ & df $P$ & value & SE & $\mathrm{t}$ & df & $\mathrm{P}$ \\
\hline$r\left(B_{j}, V_{j}\right)$ & 0.81 & 0.15 & 5.26 & $<0.001$ & 0.82 & 0.15 & -0.047 & 13 & 0.963 \\
\hline$r\left(B_{j}, P S_{j}\right)$ & 0.44 & 0.24 & & 0.087 & 0.88 & 0.13 & -4.16 & 13 & 0.001 \\
\hline$r\left(V_{j}, P S_{j}\right)$ & 0.41 & 0.24 & 1.66 & 0.112 & 0.80 & 0.16 & -2.88 & 13 & 0.013 \\
\hline
\end{tabular}


Table A8: Tests of correlations between trophic niche metrics predicted by the Niche Variation Hypothesis between and within groups of species using 41 prey categories. Correlations (value) and associated standard error (SE) are given for both observed and null data. Student statistic (t), degrees of freedom (df) and associated $P$-values $(\mathrm{P})$ are given for the tests of observed correlations being different from 0 (Observed) and from the corresponding null correlations (Comparison). The latter accounts for the fact that observed and null correlations are dependent as they share a common variable, $B_{j}$ for the first 2 ones and $V_{j}$ for the last one. Tests are performed between (Between-group correlations) and within (Within-group correlations) group of species defined according to 3 different approaches: either trait, or trophic, or phylogenetic groups. Significant $P$-values are indicated in bold.

\begin{tabular}{|c|c|c|c|c|c|}
\hline & Observed & & Null model & Comparisor & \\
\hline Correlation & value & df $P$ & value & $\mathrm{df}$ & $\mathrm{P}$ \\
\hline
\end{tabular}

Trait groups

Between-group correlations

$\begin{array}{lllllllllll}r\left(B_{j}, V_{j}\right) & 0.93 & 0.21 & 4.54 & 3 & \mathbf{0 . 0 4 0} & 0.94 & 0.19 & -0.37 & 2 & 1.000 \\ r\left(B_{j}, P S_{j}\right) & 0.49 & 0.50 & 0.97 & 3 & 0.642 & 0.96 & 0.17 & -2.62 & 2 & 0.142 \\ r\left(V_{j}, P S_{j}\right) & 0.19 & 0.57 & 0.33 & 3 & 0.764 & 0.81 & 0.33 & -2.32 & 2 & 0.293\end{array}$

Within-group correlations

$\begin{array}{lllllllllll}r\left(B_{j}, V_{j}\right) & 0.69 & 0.19 & 3.58 & 9 & \mathbf{0 . 0 1 8} & 0.65 & 0.20 & 0.41 & 8 & 1.000 \\ r\left(B_{j}, P S_{j}\right) & 0.42 & 0.24 & 1.71 & 9 & 0.365 & 0.76 & 0.17 & -2.14 & 8 & 0.193 \\ r\left(V_{j}, P S_{j}\right) & 0.57 & 0.22 & 2.60 & 9 & \mathbf{0 . 0 8 6} & 0.79 & 0.17 & -1.33 & 8 & 0.664\end{array}$

Trophic groups

Between-group correlations 


$\begin{array}{lllllllllll}r\left(B_{j}, V_{j}\right) & 0.88 & 0.24 & 3.64 & 4 & \mathbf{0 . 0 4 0} & 0.88 & 0.24 & -0.21 & 3 & 1.000 \\ r\left(B_{j}, P S_{j}\right) & 0.49 & 0.44 & 1.13 & 4 & 0.642 & 0.90 & 0.22 & -2.74 & 3 & 0.142 \\ r\left(V_{j}, P S_{j}\right) & 0.59 & 0.40 & 1.48 & 4 & 0.627 & 0.91 & 0.21 & -1.87 & 3 & 0.293\end{array}$

Within-group correlations

$\begin{array}{llllllllllll}r\left(B_{j}, V_{j}\right) & 0.55 & 0.22 & 2.45 & 8 & \mathbf{0 . 0 8 0} & 0.59 & 0.22 & -0.24 & 7 & 1.000 \\ r\left(B_{j}, P S_{j}\right) & 0.09 & 0.27 & 0.34 & 8 & 0.742 & 0.04 & 0.27 & 0.09 & 7 & 0.929 \\ r\left(V_{j}, P S_{j}\right) & -0.35 & 0.25 & -1.41 & 8 & 0.394 & -0.15 & 0.26 & -0.41 & 7 & 1.000\end{array}$

Phylogenetic groups

Between-group correlations

$\begin{array}{llllllllllll}r\left(B_{j}, V_{j}\right) & 0.95 & 0.16 & 5.79 & 4 & \mathbf{0 . 0 1 3} & 0.94 & 0.17 & 0.32 & 3 & 1.000 \\ r\left(B_{j}, P S_{j}\right) & 0.68 & 0.37 & 1.84 & 4 & 0.417 & 0.95 & 0.15 & -2.77 & 3 & 0.199 \\ r\left(V_{j}, P S_{j}\right) & 0.56 & 0.41 & 1.35 & 4 & 0.642 & 0.89 & 0.23 & -2.35 & 3 & 0.302\end{array}$

Within-group correlations

\begin{tabular}{lllllllllll}
$r\left(B_{j}, V_{j}\right)$ & 0.48 & 0.23 & 2.06 & 8 & $\mathbf{0 . 0 8 0}$ & 0.52 & 0.23 & -0.22 & 7 & 1.000 \\
$r\left(B_{j}, P S_{j}\right)$ & -0.10 & 0.27 & -0.37 & 8 & 1.000 & 0.83 & 0.15 & -2.94 & 7 & $\mathbf{0 . 0 6 5}$ \\
$r\left(V_{j}, P S_{j}\right)$ & -0.11 & 0.27 & -0.40 & 8 & 0.697 & 0.24 & 0.26 & -0.68 & 7 & 1.000 \\
\hline
\end{tabular}


a) Habitat/life history groups

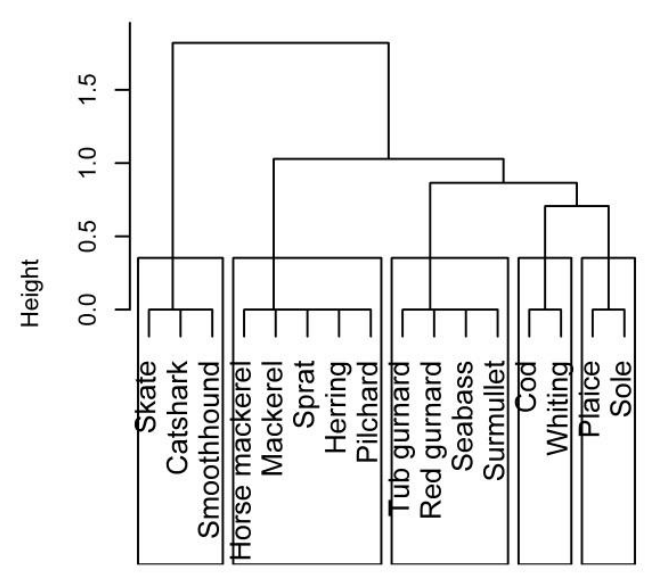

b) Trophic groups

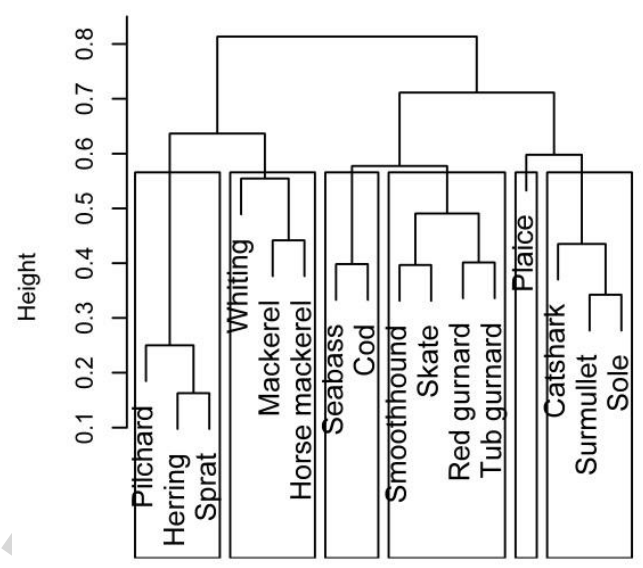

c) Phylogenetic groups

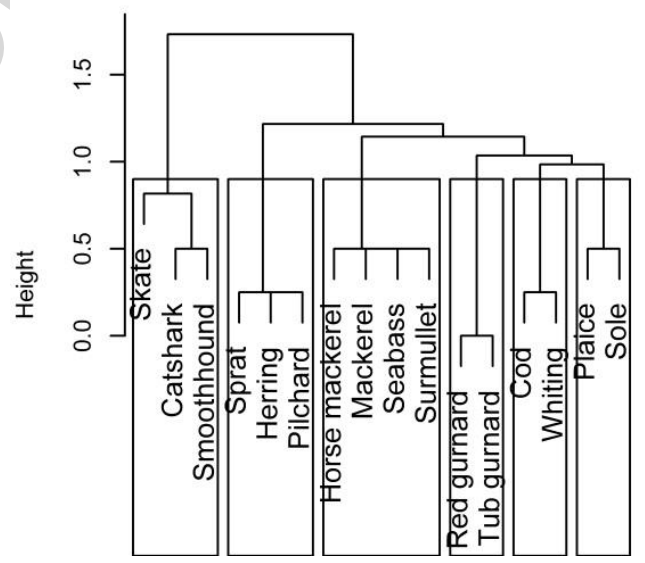

Figure A1. Functional grouping of the studied species according to a) habitat use and life history, b) clustering of species diet using 41 prey categories and c) phylogenetic relationships as inferred from taxonomy. 

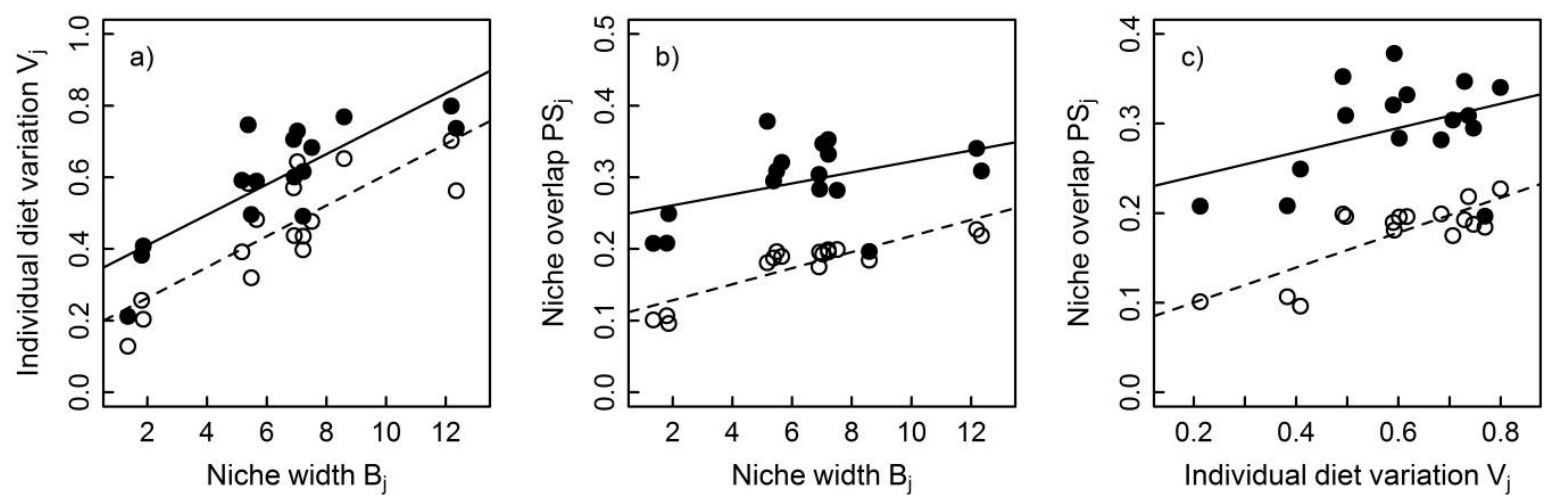

Figure A2. Correlations between trophic niche metrics predicted by the Niche Variation Hypothesis across species using 42 prey categories. a) correlation between species trophic niche width $B_{j}$ and individual diet variation $V_{j}$. b) correlation between $B_{j}$ and species trophic niche similarity $P S_{j}$. c) correlation between $V_{j}$ and $P S_{j}$. Solid circles (and black line) are observed data and related regression respectively, open circles (and dotted line) indicate data under the null hypothesis and related regression respectively. 

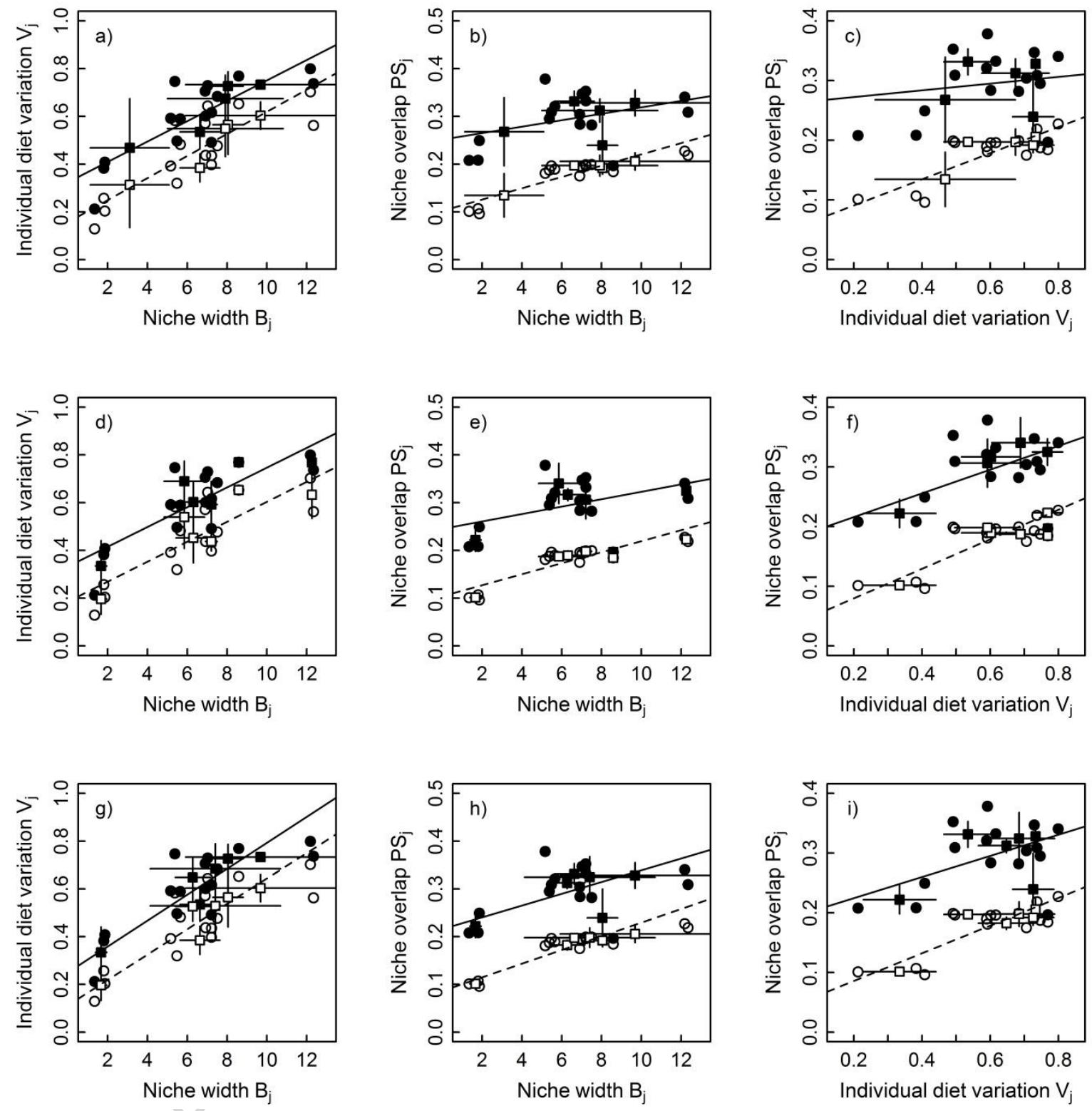

Figure A3. Correlations between trophic niche metrics predicted by the Niche Variation Hypothesis between and within group of species using 41 prey categories. a, d, g,) correlation between species trophic niche width $B_{j}$ and individual diet variation $V_{j} \cdot \mathrm{b}, \mathrm{e}, \mathrm{h}$ ) correlation between $B_{j}$ and species trophic niche similarity $P S_{j}$. c, f, i) correlation between $V_{j}$ and $P S_{j}$ . Solid circles (and black line) are observed data and related regression respectively, open circles (and dotted line) indicate data under the null hypothesis and related regression 
respectively. Niche metrics for each group (calculated as the average metric values across species affiliated to this group), their standard deviations and the related regression are depicted by solid squares, vertical-horizontal bars and the black line, respectively. Niche metrics for each group (calculated as the average metric values again), their standard deviations and the related regression under the null model are depicted by open squares, vertical-horizontal bars and the dotted line, respectively. 